\title{
EXTRACELLULAR MATRIX FRAGMENTATION IN YOUNG, HEALTHY CARTILAGINOUS TISSUES
}

\author{
R.J. Craddock ${ }^{1}$, N.W. Hodson'2, M. Ozols ${ }^{1}$, T. Shearer ${ }^{3,4}$, J.A. Hoyland ${ }^{1,5}$ and M.J. Sherratt ${ }^{1,2, *}$ \\ ${ }^{1}$ Division of Cell Matrix Biology and Regenerative Medicine, Faculty of Biology Medicine and Health, \\ The University of Manchester, Oxford Road, Manchester, M13 9PT, UK \\ ${ }^{2}$ Biological Atomic Force Microscopy Facility, Faculty of Biology Medicine and Health, \\ The University of Manchester, Oxford Road, Manchester, M13 9PT, UK \\ ${ }^{3}$ School of Materials, Faculty of Engineering and Physical Sciences, University of Manchester, \\ Oxford Road, Manchester, M13 9PL, UK \\ ${ }^{4}$ School of Mathematics, Faculty of Engineering and Physical Sciences, University of Manchester, \\ Oxford Road, Manchester, M13 9PL, UK \\ ${ }^{5}$ NIHR Manchester Biomedical Research Centre, Central Manchester University Hospitals NHS Foundation \\ Trust, Manchester Academic Health Science Centre, Grafton St, M13 9WU Manchester, UK
}

\begin{abstract}
Although the composition and structure of cartilaginous tissues is complex, collagen II fibrils and aggrecan are the most abundant assemblies in both articular cartilage (AC) and the nucleus pulposus (NP) of the intervertebral disc (IVD). Whilst structural heterogeneity of intact aggrecan ( containing three globular domains) is well characterised, the extent of aggrecan fragmentation in healthy tissues is poorly defined. Using young, yet skeletally mature (18-30 months), bovine AC and NP tissues, it was shown that, whilst the ultrastructure of intact aggrecan was tissue-dependent, most molecules (AC: $95 \%$; NP: $99.5 \%$ ) were fragmented (lacking one or more globular domains). Fragments were significantly smaller and more structurally heterogeneous in the NP compared with the AC (molecular area; AC: $8543 \mathrm{~nm}^{2}$; NP: $4625 \mathrm{~nm}^{2}$; $p<0.0001)$. In contrast, fibrillar collagen appeared structurally intact and tissue-invariant. Molecular fragmentation is considered indicative of a pathology; however, these young, skeletally mature tissues were histologically and mechanically (reduced modulus: AC: $\approx 500 \mathrm{kPa} ; \mathrm{NP}: \approx 80 \mathrm{kPa}$ ) comparable to healthy tissues and devoid of notable gelatinase activity (compared with rat dermis). As aggrecan fragmentation was prevalent in neonatal bovine AC (99.5\% fragmented, molecular area: $\left.5137 \mathrm{~nm}^{2}\right)$ as compared with mature AC $(95.0 \%$ fragmented, molecular area: $\left.8667 \mathrm{~nm}^{2}\right)$, it was hypothesised that targeted proteolysis might be an adaptive process that modified aggrecan packing (as simulated computationally) and, hence, tissue charge density, mechanical properties and porosity. These observations provided a baseline against which pathological and/or age-related fragmentation of aggrecan could be assessed and suggested that new strategies might be required to engineer constructs that mimic the mechanical properties of native cartilaginous tissues.
\end{abstract}

Keywords: Cartilage, intervertebral disc, extracellular matrix, aggrecan, glycosaminoglycans, protein structure, protein homeostasis, nanomechanics, structural biology.

* Address for correspondence: Michael Sherratt, Faculty of Biology Medicine and Health, University of Manchester, Oxford Road, Manchester, M13 9PT, UK.

Telephone: +44 1612751439 Email: michael.sherratt@manchester.ac.uk

\section{Introduction}

In mammals, avascular and extracellular matrix (ECM)-rich cartilaginous tissues resist cyclical compressive loads in articular joints and intervertebral discs (IVDs) (Colmbier et al., 2014; Musumeci et al., 2013). In these tissues, age-related degeneration has major clinical consequences, causing osteoarthritis and IVD degeneration, which contribute to chronic low back pain (Colombier et al., 2014; Greene and Loeser, 2015; Malfait, 2016; Roberts et al., 2006; Wang et al., 2016; Zhao et al., 2007). Although, collectively, these disorders cost over 100 billion dollars a year in the USA alone, the pathological mechanisms behind them remain poorly understood and it is not yet possible to reverse accumulated damage or engineer mechanically competent replacement tissues (Vedicherla and Buckley, 2016; Zeckser et al., 2016).

In order to identify the pathological mechanisms that initiate and drive degeneration and, hence, develop effective treatment strategies, it is necessary to characterise the composition and structure of 
healthy cartilage. Although the articular cartilage (AC) and nucleus pulposus (NP) of the IVD are multi-component tissues that rely on compositionally complex extracellular matrices, both tissues are composed primarily of collagen II fibrils and the large proteoglycan aggrecan, which resist tensile and compressive forces, respectively (Smith et al., 2011; Yu et al., 2007). However, there are also differences between these tissues: mechanically, the NP is significantly more compliant than AC and contains a substantially higher proportion of aggrecan (Mwale et al., 2004). Despite these differences, and in common with other ECM-rich tissues, these proteins are not only highly stable (half-lives are measured in decades), but also function as large, supra-molecular assemblies (Sivan et al., 2008; Sivan et al., 2004). Therefore, it would be beneficial to compliment transcriptomic and proteomic analyses with methods that can characterise the micro-architecture of the tissue and the supra-molecular structure of collagen fibrils and aggrecan.

Our understanding of the role played by aggrecan structure in mediating tissue mechanical properties is derived primarily from studies of the AC (Lee et al., 2013; Lee et al., 2010; Ng et al., 2003). Ng and coworker show that the structures of both, aggrecan core protein and glycosaminoaglycan (GAG) side chains, are dependent on age, species and pathology and influence the mechanical behaviour of isolated molecules ( $\mathrm{Ng}$ et al., 2003). Our knowledge of the IVD's aggrecan structure is more limited. Buckwalter and colleagues, using electron microscopy (EM), show that the mean core protein length of aggrecan monomers differs between AC and IVD, decreasing with age and varying within each tissue (Buckwalter et al., 1985; Buckwalter et al., 1989; Buckwalter et al., 1994). Although these observations of aggrecan fragmentation in young healthy tissues are confirmed by more recent studies (Lee et al., 2010; Lee et al., 2013), the extent of aggrecan fragmentation remains poorly characterised. Instead, attention has focused on the intact aggrecan population (defined as containing all three globular domains) (Lee et al., 2013; Lee et al., 2010; Roughley et al., 2014).

The perception of aggrecan as a large, uniformly structured bottlebrush is clear from schematics of cartilage structure (Sivan et al., 2014; Sophia Fox et al., 2009). However, in order to recognise age- and disease-induced molecular damage to cartilaginous tissues and design functionally competent engineered tissue replacements, it is important to understand the structural differences between AC and NP-derived aggrecan and to quantify the relative proportion of intact and non-intact molecules. In the current study, atomic force microscopy (AFM) was used in combination with solution biophysical methods to characterise and compare the structure of all aggrecan molecules isolated from the AC and NP of young, healthy cows. Nanomechanical, histological and zymography approaches were employed to confirm that these tissues were non-degenerate and not subject to excessive protease activity. Finally, the effect of aggrecan fragmentation on molecular packing was modelled computationally.

\section{Materials and Methods}

All reagents were sourced from Sigma-Aldrich (Gillingham, UK), unless otherwise stated. Bovine tissues were sourced from Kurpas Meats PLC (Manchester, UK) abattoir within $24 \mathrm{~h}$ of death. NP and AC tissue samples were dissected from bovine tail IVDs and knee joints, respectively (mature tissue from animals aged 18-30 months and immature tissue from neonates less than a week old). Dissected tissue was frozen at $-80{ }^{\circ} \mathrm{C}$ prior to aggrecan extraction. Additional tissue was prepared for histological sectioning by snap-freezing and embedding in optimal cutting temperature (OCT) compound.

\section{Aggrecan isolation by dissociative caesium chloride centrifugation}

Aggrecan was isolated from NP and AC tissues using the well-established dissociative caesium chloride $(\mathrm{CsCl})$ gradient centrifugation technique (Lee et al., 2010). Fractions with density of $1.54 \mathrm{~g} / \mathrm{mL}$ or higher (D1 fractions) were collected (in accordance with established protocols), dialysed exhaustively in phosphate-buffered saline (PBS), then diluted 1:500 with MilliQ water $(<17.3 \mathrm{M} \Omega \mathrm{cm}$ resistivity) (Lee et al., 2010).

\section{Structural characterisation of aggrecan by AFM and multi-angle light scattering}

Aggrecan structure was characterised following adsorption to a surface (AFM) and in solution (multi-angle light scattering: MALS). AFM was performed at the BioAFM facility of the University of Manchester, UK. Isolated aggrecans were prepared for visualisation as previously reported (Lee et al., 2010). AFM scans of aggrecans were captured using a PeakForce Tapping ${ }^{\mathrm{TM}}$ (ScanAsyst; Bruker, Billerica, MA, USA), in an environment with less than $45 \%$ humidity. Imaging was performed using a Multimode 8 AFM (Bruker) fitted with a "J" scanner, controlled by a Nanoscope V controller and using pyramidal ScanAyst-Air (Bruker) probes (with a nominal spring constant $k$ of $0.4 \mathrm{~N} / \mathrm{m}$ and tip radius of $2 \mathrm{~nm})$. Scan parameters were adjusted automatically by the ScanAsyst software to optimise image quality (Su et al., 2012).

Aggrecan ultrastructure was quantified from AFM height topography images $(2 \times 2 \mu \mathrm{m}$ at a sampling frequency of $3.9 \mathrm{~nm}$ ), which were flattened and converted to ASCII matrix files using WSxM 5.0 Develop 7.0 (Nanoforces Group, Madrid, Spain) (Horcas et al., 2007). The mean background was subtracted from these images using routines written in Microsoft Visual Basic 6.0. (Sherratt et al., 2004). Curved aggrecan monomers were straightened using the straighten plugin (Kocsis et al., 1991) for ImageJ 
(NIH, Bethesda, MD, USA) by manually tracing along the core protein. Then, the molecular ultrastructure of intact aggrecan monomers (comprising all three globular domains) was characterised with regards to key morphological parameters [core protein contour length $\left(\mathrm{L}_{\mathrm{CP}}\right)$, glycosaminoglycan (GAG) binding region length $\left(\mathrm{L}_{\mathrm{GAG}}\right)$ and molecular area of the aggrecan monomer covered by GAG $\left(\mathrm{MA}_{\mathrm{GAG}}\right)$ ]. GAG chain length is estimated from measurements of individual GAG chains (Lee et al., 2013). However, individual GAG chains are rarely discernible by either transmission electron microscopy (TEM) or AFM. By measuring $\mathrm{MA}_{\mathrm{GAG}}$ and $\mathrm{L}_{\mathrm{GAG}^{\prime}}$ the mean length of all GAG chains for each monomer can be calculated. Approximately 60-100 AFM scans were taken to acquire and measure sufficient intact aggrecan monomers ( $n=\approx 30-40$ per sample). Three biological replicates of unmatched AC and NP tissues were processed to characterise intact aggrecan ultrastructure (Fig. 1).

Aggrecan fragmentation was assessed in terms of the ratio of intact to non-intact aggrecan monomers and average molecular area/size for two biological replicates. The first 300-400 aggrecan monomers were identified from the original AFM scans (including both intact and non-intact) for each NP and AC sample ( $n=2$ animals). Molecular area was measured using Image (NIH) (Abramoff et al., 2004). Following subtraction of the mean average background, each AFM image underwent the following steps: (i) thresholding (using the built-in auto-threshold), (ii) analysis of particles with an area of at least 100 pixels. AFM images were analysed using MATLAB (v.
R2014a) code (Web ref. 1) written using the Miji platform (Fiji 1.3.6-fiji and MATLAB interface). This code removed noise and smoothed areas (using the "despeckle" filter) before convertion to a binary image using the default binarise command. Instrumental/ sample noise was reduced by excluding elements with a radius $<3$ pixels and infilling elements with a radius $>5$ pixels. The images were further processed using the "regionprops" function in MATLAB to select each aggrecan molecule and measure the area (number of pixels). Each molecule was skeletonised using the "bwmorph" function and the number of pixels building the resulting skeletons was used to measure aggrecan length. Aggregated molecules and sample contamination were manually excluded. The average length of the substituted sulphated GAGs was calculated for both intact molecules and total aggrecan population by dividing the molecular area by the aggrecan length, providing the area per unit of length, which was then divided by two.

As adsorption of three dimensional molecules to two dimensional surfaces inevitably affects their structure (Sherratt et al., 2004), the structure of ACand NP-derived aggrecan was also characterised by size-exclusion chromatography with multi-angle light scattering [SEC-MALS; (Jowitt et al., 2010)]. Purified suspensions were chromatographed on a Shodex 806M SEC gel filtration column (Shodex, Munich, Germany), in phosphate-buffered saline (PBS) Dulbecco's A ( $n=3 ; 0.137 \mathrm{M} \mathrm{NaCl}$; OXOID, Thermo Scientific, Waltham, MA, USA), driven by a Bio-Rad GPC system (Bio-Rad, Hercules, CA, USA) at $0.75 \mathrm{~mL} / \mathrm{min}$ used in conjunction with a DAWN

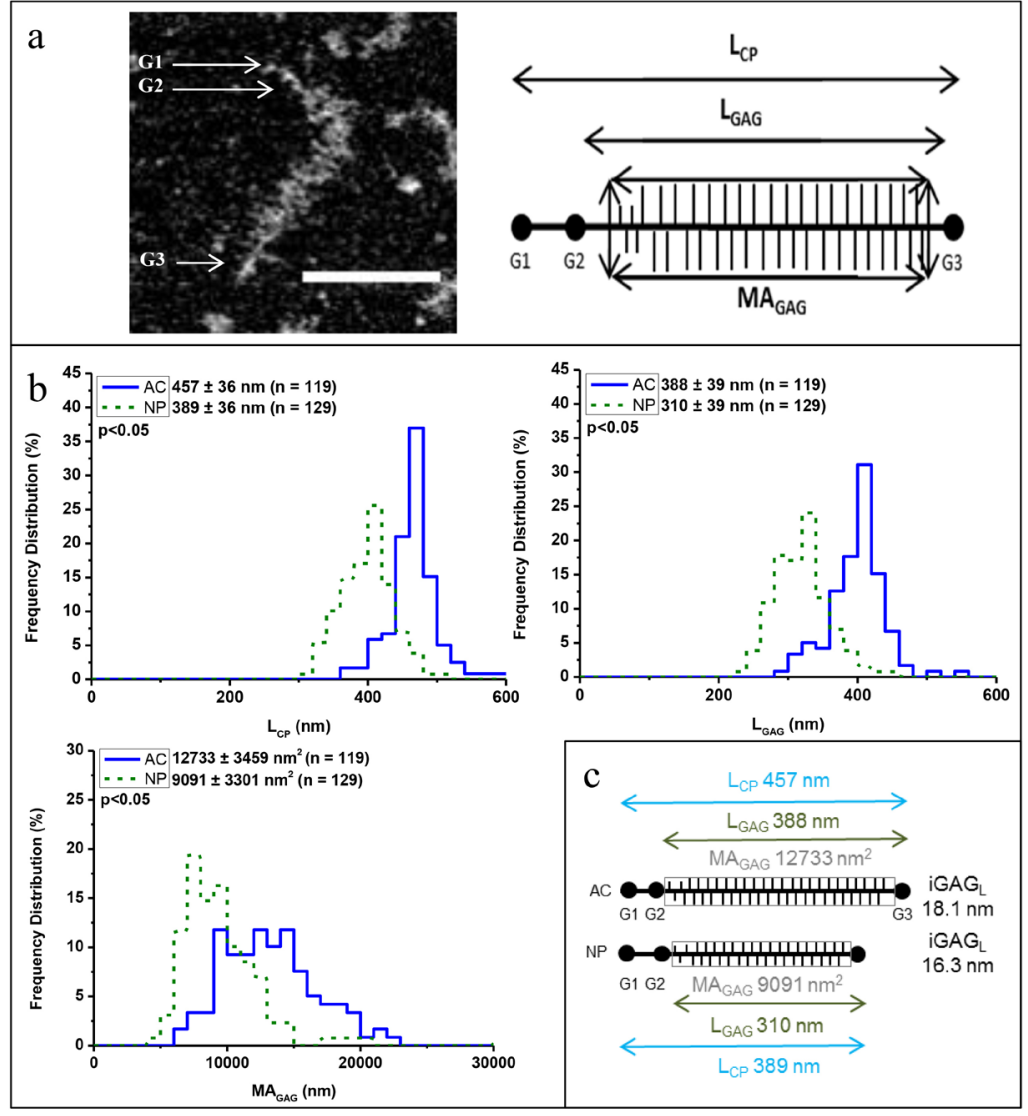

Fig. 1. Surface-adsorbed intact aggrecan monomers were structurally dissimilar in the NP and AC tissues. (a) AFM height image (scale bar: $0.2 \mu \mathrm{m}$; z-scale: $2 \mathrm{~nm}$ ) of an intact aggrecan monomer comprising three globular (G1-G3) domains. Three structural parameters were measured for each intact monomer: core protein length $\left(\mathrm{L}_{\mathrm{CP}}\right)$, GAG length $\left(\mathrm{L}_{\mathrm{GAG}}\right)$ and molecular area $\left(\mathrm{MA}_{\mathrm{GAG}}\right)$. (b) Combined frequency distributions and mean \pm standard deviation (SD) of $\mathrm{L}_{\mathrm{CP}^{\prime}} \mathrm{L}_{\mathrm{GAG}}$ and $\mathrm{MA}_{\mathrm{GAG}}$ for $n=3 \mathrm{NP}$ and AC replicates. (c) Relative mean molecular dimensions of intact AC- and NP-derived aggrecan monomers. 
HELEOS II MALS system with a Wyatt-288-H2 QELS detector (Wyatt Technologies, Santa Barbara, CA, USA). The absolute molecular mass, polydispersity index and root mean square (RMS) conformation of the isolated aggrecan was calculated using the supplied Astra 6.1 software (Jowitt et al., 2010). MALS was also used to determine shape (e.g. cylindrical/ rod-like or globular/spherical) of aggrecan monomers across a range of salt concentrations $(0.001 \mathrm{M} \mathrm{NaCl}$, PBS and $1 \mathrm{M} \mathrm{NaCl}$ ) using RMS conformation.

Histological assessment of tissue composition and collagen fibril alignment

The relative abundance (area fraction) of collagen fibril bundles within a tissue can be semi-quantitatively assessed using picrosirius red (PSR) staining to enhance collagen birefringence. AC and NP tissues were cryosectioned to a nominal thickness of $7 \mu \mathrm{m}$, PSR-stained and visualised under cross-polarised light, as previously described (Graham et al., 2011; McConnell et al., 2016). Three locations per AC (articular surface, superficial zone and middle zone) and NP (three equidistant points, as NP tissue is homogenous) cryosections were analysed in three biological replicates. GAG content in adult tissues was determined by safranin $\mathrm{O} /$ fast green and alcian blue $\mathrm{pH} 2.5$ stains.
Characterisation of collagen fibril ultrastructure by atomic force microscopy

Collagen fibril periodicity and orientation was assessed in situ in $10 \mu \mathrm{m}$-thick tissue cryosections (Fang et al., 2012; Graham and Trafford, 2007; Graham et al., 2004; Sherratt et al., 2004). In order to disclose the underlying collagen network, NP tissue was treated with 400-1000 U/mL bovine hyaluronidase (Plodinec et al., 2010) and allowed to air-dry for several hours at room temperature prior to AFM scanning. Collagen fibrils were visualised by tapping-mode AFM in air using a Catalyst AFM, Nanoscope V controller and pyramidal OTESPA probe (Bruker; nominal spring constant $k=12-103 \mathrm{~N} / \mathrm{m}$, nominal tip radius $=7 \mathrm{~nm}$ ). The amplitude set-point was adjusted to optimise image quality. Collagen fibril periodicity and orientation were determined from amplitude images $(4 \times 4 \mu \mathrm{m}$ at a sampling frequency of $3.9 \mathrm{~nm})$. Images were processed using the 2D Fast Fourier Transform [2D FFT (periodicity)] and power spectrum density (orientation) tools found within WSxM (Nanoforces Group) (Wallace, 2015). Orientation coherency was assessed using the OrientationJ plugin in ImageJ (NIH), which calculates the average vector across an image and expresses the orientation coherency (percentage of pixels that are aligned in the same direction) (Rezakhaniha et al., 2012). This analysis

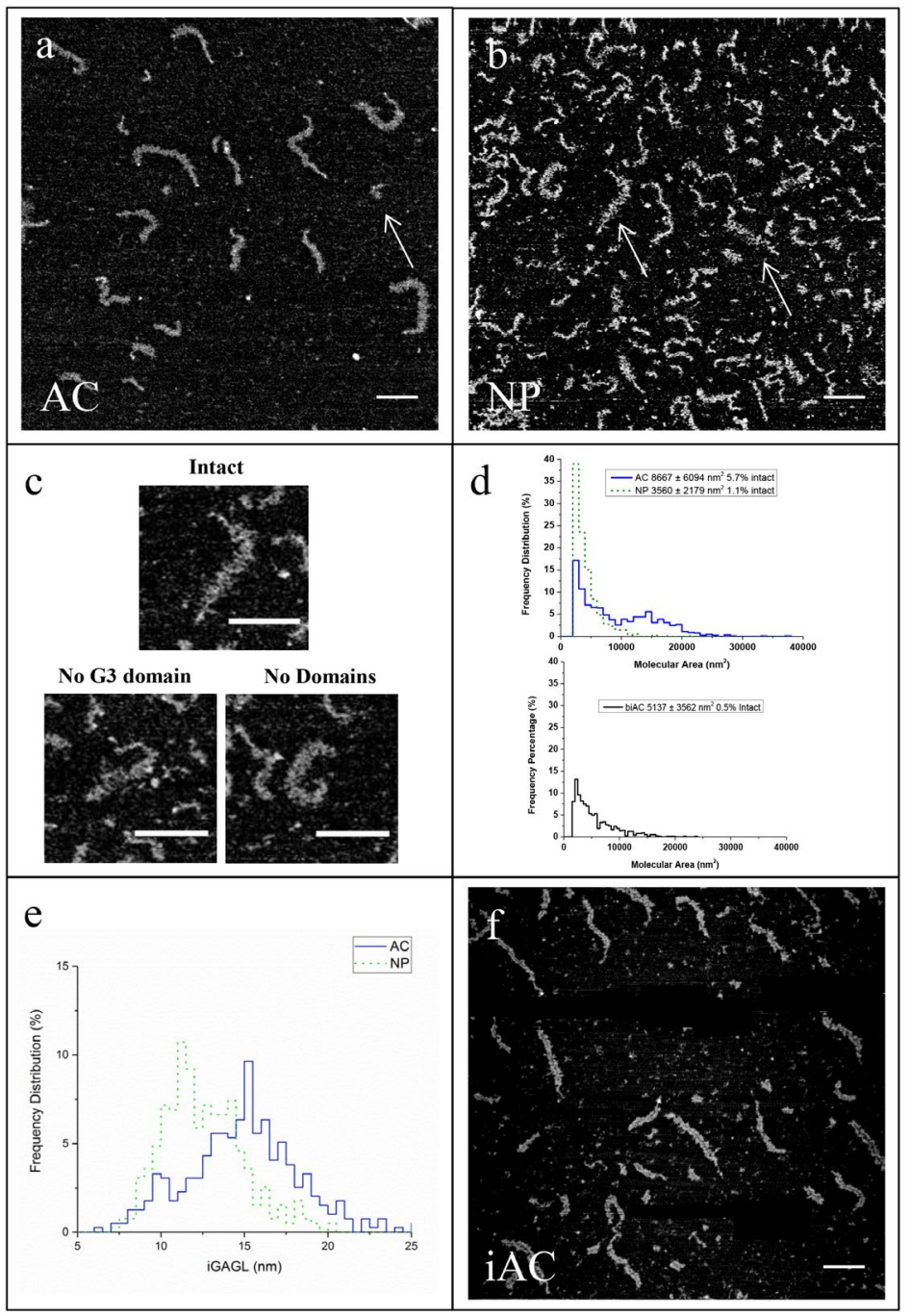

Fig. 2. AC and NP were composed primarily of fragmented aggrecan. AFM height images of (a) AC and (b) NP isolated aggrecan molecules (image size: $2 \times 2 \mu \mathrm{m}$; scale bar: $0.2 \mu \mathrm{m}$; z-scale: $2 \mathrm{~nm}$ ). Arrows indicate intact monomers. (c) Only a small proportion of aggrecan molecules were in the intact form. Most molecules lacked either the G3 domain or all globular domains. (d) Molecular area size distribution of fragments of all observable (i.e. both intact and non-intact) aggrecan, regardless of fragment size or orientation, in skeletally mature AC and NP ( $n=3$ biological replicates) and immature AC ( $n=2$ biological replicates). (e) $i_{G A G_{L}}$ of all observable aggrecan molecules in skeletally mature AC and NP $(n=3$ biological replicates). (f) Representative AFM image of aggrecan isolated from immature AC (image size: $2 \times 2 \mu \mathrm{m}$; scale bar: $0.2 \mu \mathrm{m}$ ). Values shown within the histograms represent mean \pm SD. 
was repeated across 4 sites per AC and NP sample (biological replicates $n=3$ ).

Collagen fibril diameter was quantified by characterising the height of isolated fibrils. AC and NP tissue samples were dissected into small pieces, digested with hyaluronidase, re-suspended in PBS and homogenised as previously described (Plodinec et al., 2010). Approximately $10 \mu \mathrm{L}$ of the collagen fibril isolate was pipetted onto an uncoated glass slide, air-dried at room temperature, washed with MilliQ water and then air-dried again prior to visualisation by tapping-mode AFM. Collagen fibril diameter was quantified from $1^{\text {st }}$-order-flattened AFM height images. 10 transverse profile measurements were taken across 50 individual isolated collagen fibrils per sample and average diameter was calculated (biological replicates $n=2$ ).

\section{Measurement of nanomechanical compressive stiffness by AFM indentation}

The compressive (reduced) modulus of hydrated tissue cryosections was assessed at the nanometre scale by AFM nanomechanical assessment on a Bruker Catalyst AFM with a Nanoscope V controller (Su et al., 2012). $20 \mu \mathrm{m}$-thick AC and NP cryosections were adsorbed to SuperFrost Plus slides (Thermo Scientific), air-dried for $24 \mathrm{~h}$, washed with MilliQ water to remove OCT and rehydrated for $1 \mathrm{~h}$ prior to mechanical assessment. AC and NP tissue sections were characterised using a pyramidal ScanAsystFluid probe (Bruker; nominal spring constant $k=0.7 \mathrm{~N} / \mathrm{m}$, nominal tip radius $=20 \mathrm{~nm}$ ) and a more compliant pyramidal MLCT-E probe (Bruker; nominal spring constant $k=0.1 \mathrm{~N} / \mathrm{m}$, tip radius $20 \mathrm{~nm})$, respectively. Four $100 \mu \mathrm{m}^{2}$-large cryosections were assessed $(\approx 400$ points per site). In the AC, these sites were localised from the cartilage superficial zone to the deep zone ( $n=3$ biological replicates); for the NP, in the middle zone $(n=3$ biological replicates) (Fig. 6). The AC tissue was probed at a scanning rate of $1 \mathrm{~Hz}$ and an indentation depth of only $20 \mathrm{~nm}$, to avoid the influence of the stiff glass substrate. The more compliant NP tissue was probed at a scanning rate of $0.250 \mathrm{~Hz}$, an indentation depth of $20 \mathrm{~nm}$ and a retracted delay of $1 \mathrm{~s}$. Force curves, with a calculated reduced modulus greater than two standard deviations from the mean, were excluded and the mean reduced modulus during extension was derived by Nanoscope Analysis software (Bruker) using a Sneddon (conical) contact point based model (McConnell et al., 2016).

\section{Relative gelatinase activity determined by in situ gelatinase zymography}

To analyse the proteolytic environment in the tissues, in situ gelatine zymography was used to compare gelatinase activity in bovine AC and NP with a tissue, young healthy rat dermis, which displays minimal gelatinase activity (Tewari et al., 2014). Matrix metalloproteinases (MMPs) are synthesised and sequestered in tissues in an inactive form. Therefore, MMP expression and immunohistochemical localisation alone are poor predictors of protease activity (Chakraborti et al., 2003). MMPs (i.e. MMP-1, $-2,-3,-7,-8,-9,-10,-13)$ and cathepsins $\mathrm{K}$ and $\mathrm{L}$ are found in both IVD and AC (Ariga et al., 2001; Chakraborti et al., 2003; Gruber et al., 2011; Konttinen et al., 1999; Vo et al., 2013), exhibit gelatinase activity and are capable of proteolytically cleaving both aggrecan and gelatine (collagen). As such, the active forms of these enzymes can be detected by in situ gelatine zymography (Chakraborti et al., 2003; Fosang et al., 1992; Hou et al., 2003; Konttinen et al., 2002; Nguyen et al., 1991; Nguyen et al., 1990; Pelletier et al., 2005). Gelatinase activity was localised and quantified in $15 \mu \mathrm{m}$-thick tissue cryosections cut from young, healthy bovine AC and NP tissues $(n=2)$ and from healthy rat skin $(n=1)$, as previously described (Akhtar et al., 2014). Young healthy rat dermis displays minimal activity (Tewari et al., 2014), is relatively acellular and is primarily composed of extracellular matrix assemblies, such as fibrillar collagens and elastic fibres with halflives measured in many decades (Sherratt, 2009). Fluorescent imaging was performed at an exposure time of $200 \mathrm{~ms}$. Gelatinase activity was quantified using Image ( $\mathrm{NIH}$ ): mean fluorescence intensity was quantified from the surface to a depth of $\approx 150 \mu \mathrm{m}$ [AC: surface to the middle/deep zones $(n=3)$ and skin epidermal surface to dermis $(n=1)]$. In NPs, fluorescence activity measurements were taken over a $150 \mu \mathrm{m} \times 150 \mu \mathrm{m}$ area $(n=3)$. Using Image $(\mathrm{NIH})$, background fluorescence was removed across each tissue section to determine mean gelatinase activity/ fluorescent intensity. Tissue auto-fluorescence was accounted for using an unstained control.

\section{Computational modelling of aggrecan packing}

To model the potential effects of aggrecan fragmentation on molecular packing within tissues, a simulation was developed using Mathematica 11.0 (Wolfram Research, Inc., Champaign, IL, USA; 2008 version), which randomly places aggrecan monomers and/or fragments within a virtual cubic volume of side length 40 (all lengths are nondimensionalised on the aggrecan monomer radius, which was assumed to be constant). Based on the MALS data, aggrecan monomers were modelled as rigid cylinders with hemispherical ends. One end of each cylinder was randomly located within the volume by selecting a random coordinate within the range $(0,0,0)$ to $(40,40,40)$, then the orientation of the cylinder relative to that point was defined by a unit vector in a spherical coordinate system described by azimuthal angle $\theta$ and polar angle $\varphi$, which were randomly selected from the ranges $\theta \in\{0, \pi\}$ and $\varphi \in\{0, \pi\}$ (molecular extremities were allowed to project beyond the volume boundaries). Newly placed cylinders were rejected if they overlapped with an existing cylinder (failed placement). This process was repeated until a critical number $c$, of failed placements, was reached, at which point the 
algorithm terminated. To determine an appropriate value for $c$, the final aggrecan volume fraction, $f$, was monitored as $c$ was increased in increments of 100 until $f$ no longer increased (Fig. 8a). The final value used for all simulations was $c=700$. Three simulated molecular populations were investigated, which were categorised according to their length (relative to their radius): i) the experimental population had a distribution of (relative) lengths defined by a gamma distribution, which was fitted to the experimental data for NP aggrecan and found to have shape parameter $\alpha=2.97$ and scale parameter $\beta=3.02$; ii) the intact population had a constant (relative) length of 17.3, which was the average (relative) length calculated from the experimental data on intact NP aggrecan; iii) the fragmented population had constant (relative) length, which was a quarter of the length of the intact population. Then, the influence of molecular length on total aggrecan volume fraction was determined for each of the three populations ( $n=12$ simulations/ population) by determining which fraction of the central region of the cube [another cube of side length 20 with opposite corners at the points $(10,10,10)$ and $(30,30,30)]$ was occupied.

\section{Statistical Analysis}

Statistical significance for aggrecan structure and collagen fibril diameter characterisation was calculated using the non-parametric Mann-Whitney $\mathrm{U}$ test $(p<0.05)$. Statistical analysis of parametric data for collagen periodicity, birefringence and in situ gelatine zymography was performed using the unpaired Student's t-test.

\section{Results}

The ultrastructure of intact aggrecan monomers was tissue-specific

Intact aggrecan molecules adsorbed to a surface can be readily identified and ultrastructure characterised by AFM or EM (Buckwalter et al., 1985; Lee et al., 2013; Lee et al., 2010). AFM was used to compare three structural parameters of intact AC- and NP-derived aggrecan
$\left(\mathrm{L}_{\mathrm{CP}^{\prime}} \mathrm{L}_{\mathrm{GAG}}\right.$ and $\left.\mathrm{MA}_{\mathrm{GAG}}\right)$ (Fig. 1a). Mean aggrecan $\mathrm{L}_{\mathrm{CP}}$ was significantly lower for NP- $(395 \pm 36 \mathrm{~nm})$ compared to AC- $(460 \pm 30 \mathrm{~nm})$ derived aggrecan $\left(p<0.05\right.$, Fig. 1b). Similarly, the mean lengths $\left(\mathrm{L}_{\mathrm{GAG}}\right.$ : $\mathrm{NP}=310 \pm 39 \mathrm{~nm}$ and $\mathrm{AC}=393 \pm 31 \mathrm{~nm})$ and areas $\left(\mathrm{MA}_{\mathrm{GAG}}: \mathrm{NP}=9091 \pm 3301 \mathrm{~nm}^{2}, \mathrm{AC}=12652 \pm 3573 \mathrm{~nm}^{2}\right)$ of the glycosylated regions were significantly shorter and smaller, respectively, in NP compared with AC intact aggrecan $(p<0.05$; Fig. 1b). Average GAG chain length was significantly different between AC and NP ( $p<0.01,18.1 \mathrm{~nm}$ and $16.3 \mathrm{~nm}$, respectively). Therefore, it was clear that the ultrastructure of intact aggrecan differed between the two tissues.

\section{Most isolated aggrecan molecules were fragmented and structurally heterogeneous}

In a typical AFM height image of AC and NP-derived aggrecan (Fig. 2a,b), only two out of $\approx 100$ (NP) and 2 out of 16 (AC) molecules were intact. The remaining were either missing the C-terminal G3 domain or had no visible globular domains and varied considerably in length (Fig. 2c). In the total molecular population (AC $n=933$; NP $n=1061$ ), fragmented aggrecan accounted for $95 \%$ of the observed molecules in AC and $99.5 \%$ in NP. Aggrecan fragmentation was more pronounced in NP compared with AC in all three biological replicates and consequently the mean molecular area was significantly lower for NP compared with AC (4625 $\mathrm{nm}^{2}$ and $8543 \mathrm{~nm}^{2}$, respectively; $p<0.0001$ ) (Fig. 2d). Mean GAG chain length $\left(\mathrm{iGAG}_{\mathrm{L}}\right.$ ) was also significantly lower in NP compared with AC tissue (12.1 nm and $14.5 \mathrm{~nm}$, respectively; $p<0.0001$ ) (Fig. 2e). As aggrecan fragmentation is identified as being a consequence of ageing (Sivan et al., 2014), it was next determined if fragmentation in mature, yet young ( $<30$ months), animals was indicative of early onset age-related degeneration and, thus, aggrecans from the AC of neonatal calves were isolated. Immature bovine AC contained an even smaller proportion of intact aggrecan $(0.5 \%$, $n=792)$ than mature AC $(5 \%, n=933)$ and the mean molecular area of the total aggrecan population was also significantly lower $\left(5137 \mathrm{~nm}^{2}\right.$ and $8667 \mathrm{~nm}^{2}$, respectively; $p<0.0001$ ) (Fig. 2d).

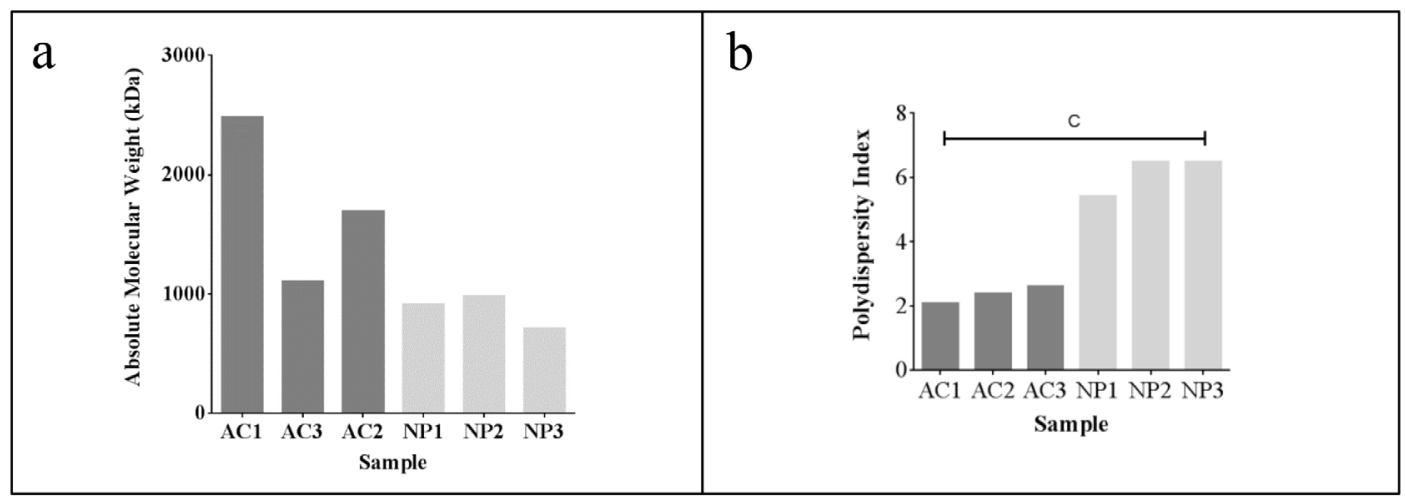

Fig. 3. Polydispersity of solution aggrecan indicated that aggrecans were highly fragmented and structurally heterogeneous. The structure of AC- and NP-derived aggrecans was characterised by MALS in PBS: (a) absolute molecular weight and (b) polydispersity index. $C$ indicates a significance of $p<0.001$. 
To exclude the possibility that the apparent dominance of fragmented aggrecan was due to preferential adsorption of non-intact species and also to avoid the influence of surface chemistry on molecular structure, a complimentary biophysical technique (SEC-MALS) was used to characterise aggrecan structure in solution (Chandran et al., 2010; Kienle et al., 2014; Sherratt et al., 2004). SECMALS was used to assess the mean absolute molecular weight $(\mathrm{Mw})$, polydispersity (a measure of structural heterogeneity) and elongation (RMS conformation) of aggrecan isolated from mature $\mathrm{NP}$ and AC tissue ( $n=3$, biological replicates) at physiological salt concentrations. Although there was no significant difference in the $\mathrm{Mw}$ of $\mathrm{AC}$ and NP-derived aggrecans $(1762 \pm 692 \mathrm{kDa}$ and $867 \pm 139$ kDa, respectively; Fig. 3a), AC-derived aggrecans were more elongated compared to NPderived aggrecans (RMS values of 0.54 and 0.45 , respectively). Additionally, NP-derived aggrecans were approximately 2-3 times more polydisperse than AC-derived (5.95 and 2.28, respectively, $p<0.001$; Fig. $3 \mathbf{b}$ ). Thus, whether characterised in solution or adsorbed to a surface (by AFM), there were structural differences between AC- and NP-derived aggrecans and both tissues resulted composed of highly fragmented and heterogeneous molecules.
Aggrecan fragmentation was not associated with aberrant structural or mechanical tissue remodelling or excessive protease activity

As molecular fragmentation is usually considered to be indicative of ageing and/or disease (El Bakali et al., 2014; Sztrolovics et al., 1997), the histological composition, collagen ultrastructure and micromechanical properties of young, mature AC and NP (Fig. 4) were characterised. Whilst there are well-established GAG-specific stains, such as alcian blue and safranin $\mathrm{O}$, there are no reliable techniques for the histological quantification of aggrecan and, therefore, it was not possible to quantify GAG abundance in our isolated aggrecan suspensions using existing biochemical assays. However, both AC and NP stained positively for GAGs and there was no evidence of a reduced safranin $\mathrm{O}$ staining, which is indicative of cartilage degeneration (Musumeci et al., 2013). In contrast, fibrillar collagen content can be semi-quantitatively characterised histologically by measuring PSR-enhanced collagen birefringence (McConnell et al., 2016). In accordance with previous studies of healthy tissue (Iijima et al., 2014; Issy et al., 2013), the AC was enriched in fibrillar collagen $(75.5 \pm 13.6 \%)$ compared with the NP $(33.0 \pm 7.60 \%)$ $(p<0.01)$. Conversely, the NP was qualitatively enriched in GAGs compared with the AC (Fig. 4).
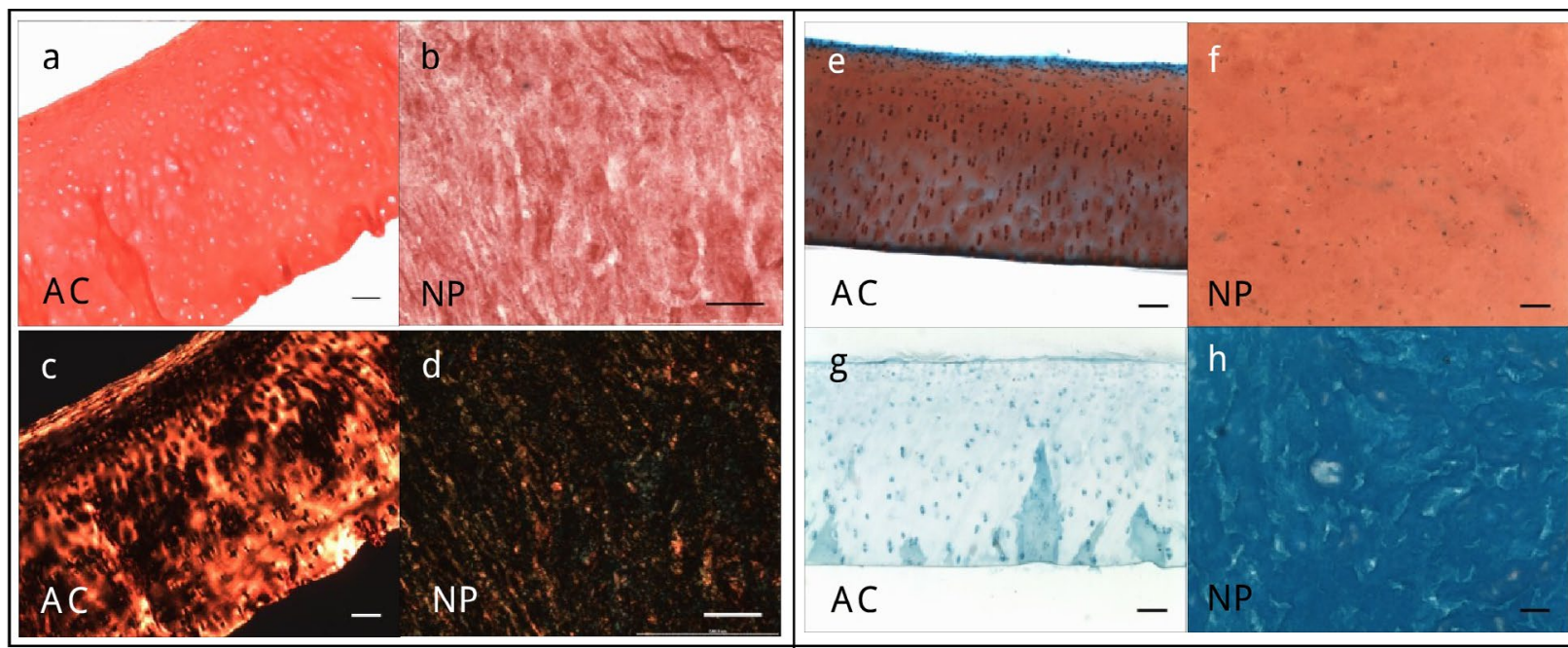

Fig. 4. Young, mature tissues showed no signs of histological degeneration. Images are representative of three biological replicates for mature and immature AC and NP tissues. Scale bars: $100 \mu \mathrm{m}$. $(\mathbf{a}, \mathbf{b})$ Bright-field images of PSR staining (mature); (c,d) polarised light images of PRC staining revealing fibrillar collagen (mature); (e,f) safranin $\mathrm{O} /$ fast green staining (mature); (g,h) alcian blue pH 2.5 staining (mature); $(\mathbf{i}, \mathbf{j})$ safranin $\mathrm{O} /$ fast green staining (immature); (k,1) alcian blue pH 2.5 staining (immature).

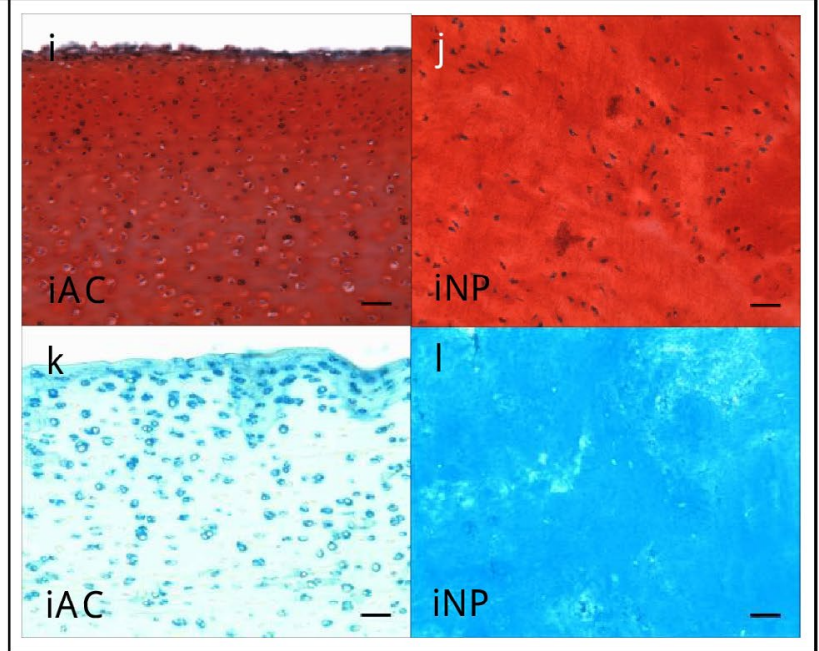


Although these histological observations suggested that the tissues used in this study were healthy, collagen fibril morphology, tissue nanomechanics and protease activity were further characterised.

AFM and PSR staining/polarised light microscopy were used to characterise collagen fibril morphology and architecture (periodicity and orientation) both in situ and as isolated fibrils (diameter). Collagen fibril periodicity was invariant between AC and NP (mean of $63.48 \mathrm{~nm}$ ) (Fig. 5a) and both tissues were composed of two fibrillar populations, which differed in diameter (thick: $\mathrm{AC}=139.3 \mathrm{~nm}, \mathrm{NP}=141.4 \mathrm{~nm}$; thin: $A C=120.03$ nm, NP = 19.93 nm) (Fig. 5d). The presence of thick and thin collagen II fibrils in the AC is well established (Holmes and Kadler, 2006), but, to our knowledge, this was the first report of thick collagen fibrils in the NP. In our samples, no evidence of fibril alignment was observed either by AFM (Fig. 5c) or histologically (AC alignment: $0.076 \%$; NP alignment: $0.096 \%$ ) (Fig. 4c,d). As the ECM structure mediates tissue mechanical properties (Akhtar et al., 2011), pathological fragmentation of aggrecan would be expected to alter the compressive modulus (Sivan et al., 2014). Using AFM indentation, the mean reduced modulus of AC was measured to be $497 \pm 232 \mathrm{kPa}$ (Fig. 6), which is comparable with previously reported values for healthy tissue (Treppo et al., 2000). NP tissue was found to be significantly more compliant than AC (reduced compressive modulus of $76.7 \pm 48.1 \mathrm{kPa}$; Fig. 6). However, it should be noted that these moduli relate to stiffness at the molecular length scale and that the measured stiffness at micro and millimetre length scales is likely to differ (Akhtar et al., 2011).

Finally, degeneration of cartilaginous tissues is commonly associated with the upregulation of protease expression and activity (El Bakali et al., 2014). However, in situ gelatine zymography (Fig. 7) demonstrated that, regardless of age, gelatinase activity was predominantly localised at the surface of $\mathrm{AC}$ and homogenously distributed throughout the NP, with no significant difference between immature and mature AC and NP (immature AC: $50.25 \pm 29.66$ pixels; immature NP: $51.81 \pm 32.55$ pixels; mature AC: $58.37 \pm 56.51$ pixels; mature NP: $35.53 \pm 10.45$ pixels). Importantly, both rat skin

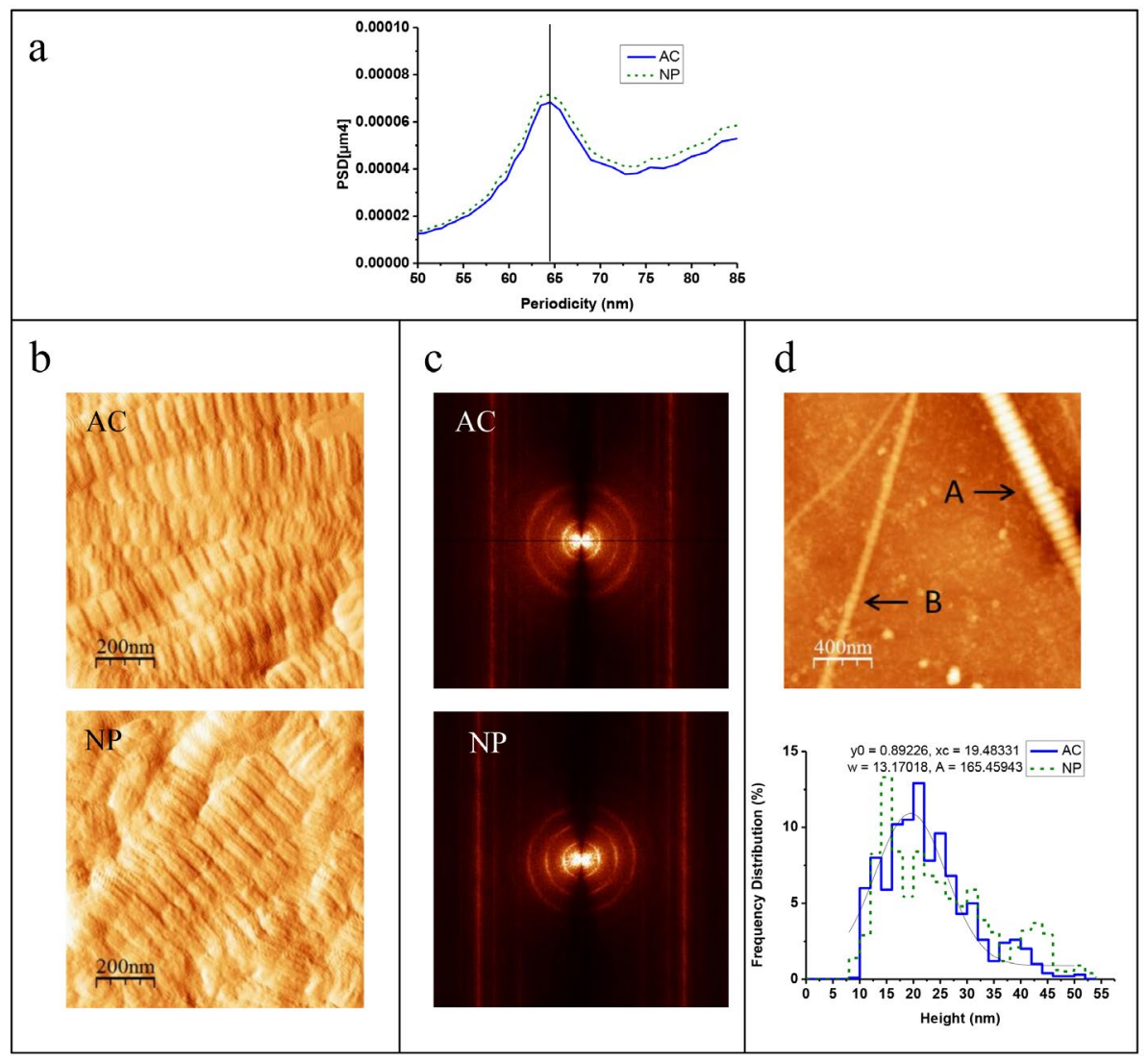

Fig. 5. Collagen fibril ultrastructure and architecture in mature AC and NP. Data are representative of two biological replicates for AC and NP. (a) Topographical amplitude images representative of native AC and NP (proteogylcans were digested from the NP tissue in order to reveal collagen fibrils). (b) Topographical height image of in situ collagen fibrils in AC and NP. (c) Orientation and periodicity of collagen fibrils in situ in AC and NP measured using 2D Fourier transform (2D-FFT). The first ring in the image corresponds to the fundamental frequency (due to collagen periodicity). The presence of rings rather than spots indicated that the fibrils had no preferred alignment. (d) Topographical height image of isolated collagen fibrils highlighting two distinct populations present in the AC and NP. Histogram fitted with Gaussian curves showing the distribution of the diameters of the two populations of collagen fibrils isolated from the AC and NP. 
epidermis and hypodermis exhibited significantly higher levels of fluorescence and, therefore, gelatinase activity (epidermis: $128.9 \pm 49.73$ pixels; hypodermis: $175.0 \pm 15.13$ pixels; $p<0.0001)$ than either bovine AC or NP (Fig. 7b). Therefore, it appeared that these tissues exhibited no signs of pathological remodelling with regards to collagen fibril and GAG composition, collagen fibril ultrastructure and alignment and micro-mechanical stiffness or ECM protease activity.

\section{Aggrecan fragmentation was predicted to modulate molecular packing density}

In order to characterise the potential influence of aggrecan fragmentation on cartilage and NP structure, computational approaches were initially used to model the effects of molecular dimension on predicted packing density. Molecular dimensions in solution were characterised experimentally by MALS of isolated aggrecan in low $(10 \mathrm{mM}$ $\mathrm{NaCl})$, physiological $(136 \mathrm{mM})$ and high $(1 \mathrm{M})$ salt conditions. Salt concentration mediates interactions between GAG chains and, therefore, the aggrecan morphology (Chandran et al., 2010; Chandran and Horkay, 2012; Ng et al., 2003). Aggrecan elongation is inversely correlated to salt concentration (Chandran et al., 2010; $\mathrm{Ng}$ et al., 2003) and RMS conformation values for both $\mathrm{NP}$ - and AC-derived aggrecan were between $0.5-0.8$, suggesting that the molecule had a rod-like structure in solution (Kulicke and Clasen, 2004).

Therefore, individual aggrecan molecules were modelled as rigid cylinders with hemispherical ends. Population dimensions were modelled as experimental (drawn from the experimentally determined length distributions), intact and fragmented (one quarter length). Using the experimental population, it was established that a cut-off of 700 failures indicated a virtually saturated volume (Fig. 8a). Using this cutoff and 12 computational simulations for each length distribution, it was clear that the experimental length distribution not only resulted in a higher packing density $(10.01 \pm 0.72 \%)$ than either intact $(9.85 \pm 1.40 \%)$ or fragmented $(9.27 \pm 0.75 \%)$ distributions (significant for experimental $v s$. fragmented, $p<0.05$, Student's $t$-test), but also reduced heterogeneity (Fig. $8 \mathbf{b}$ ). These simulations suggested that partial fragmentation of aggrecan might confer an advantage by promoting uniformly dense packing and, therefore, higher charge density, osmotic potential and mechanical stiffness. However, it should be emphasised that these simulations do not consider the influence of other tissue components (such as collagen II and hyaluronic acid), intermolecular interactions and variations in GAG chain length. The validity of these predictions on, for example, porosity could be tested using in vitro model systems employing tuneable aggrecan molecules or mimetics and techniques such as fluorescence recovery after photo-bleaching (Gribbon et al., 1998).

\section{Discussion}

The results of this study demonstrated that the molecular structure of aggrecan was highly heterogeneous in developing and mature (yet young) tissues and suggested, using modelling approaches, that programmed fragmentation might be an adaptive process to optimise tissue structure and function.

Previous studies have focused attention on the structure of intact aggrecan. In this study, a small population of intact aggrecan monomers, structurally similar to those reported for equine $\mathrm{AC}$ tissues and

\section{a}
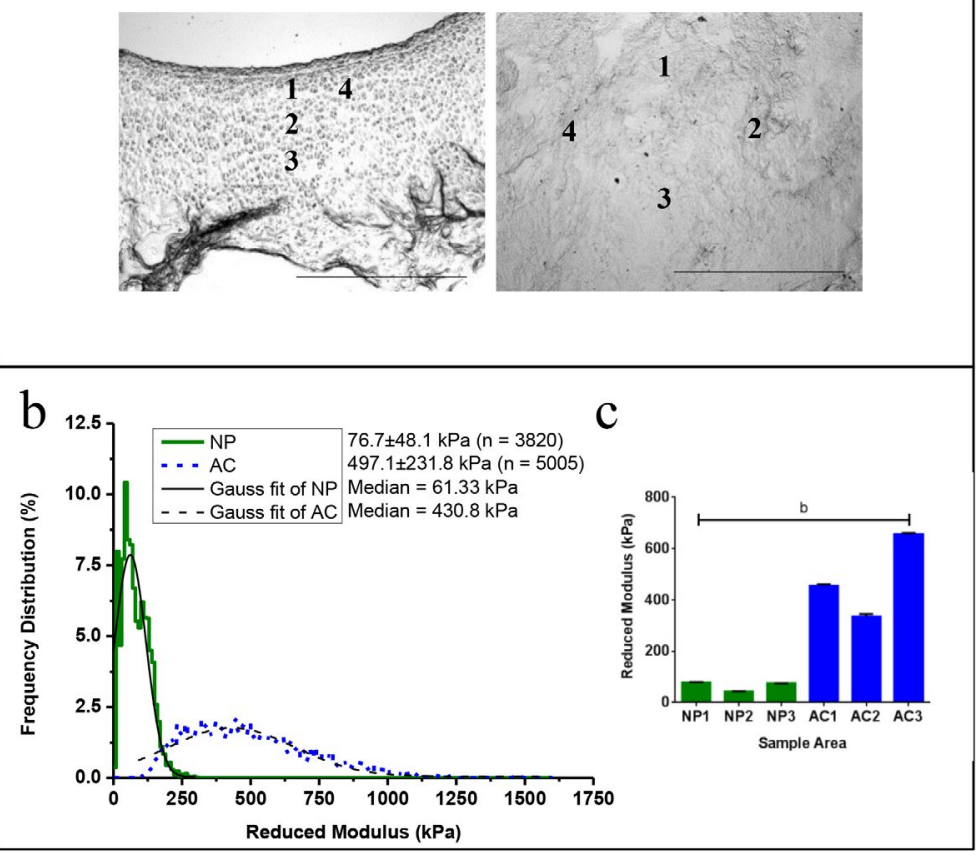

Fig. 6. AC is significantly stiffer than NP. Data are representative of three biological replicates for AC and NP tissue. (a) Optical images representative of native AC and NP tissue identifying the location of mechanical measurements (14). Scale bar: $1 \mathrm{~mm}$. (b) AFM quantitative nanomechanical property mapping (QNM) data displayed as a histogram fitted with Gaussian curves. (c) Bar chart displays the mean reduced modulus \pm standard error. $b$ indicates a significance of $p<0.001$. 
equine bone marrow mesenchymal stem cells, was observed (Lee et al., 2010). However, these intact monomers had a smaller $\mathrm{L}_{\mathrm{CP}}$ compared to young and adult human AC (Lee et al., 2013). Importantly, $\mathrm{L}_{\mathrm{CP}}$ was shown to be significantly shorter (by $\approx 60 \mathrm{~nm}$ ) in NP-compared to AC-derived aggrecan, due to a reduction in $\mathrm{L}_{\mathrm{GAG}}$ and $\mathrm{MA}_{\mathrm{GAG}}$. This difference in $\mathrm{L}_{\mathrm{CP}}$ combined with the reduced protein elongation in solution, pointed to a variability in the biosynthesis/ glycosylation of aggrecan rather than alternative splicing, which is restricted to the C-terminal G3 domain and does not appear to affect $\mathrm{L}_{\mathrm{CP}}$ (Sivan et al., 2014). Differential glycosylation could alter aggrecan length, as reduced GAG load might cause NP-derived aggrecan to adopt a lower energy state and, hence, a relaxed random coil as opposed to an extended, rigid structure ( $\mathrm{Ng}$ et al., 2003). GAG chain length (and charge density) impacts on tissue stiffness ( $\mathrm{Ng}$ et al., 2003; Lee et al., 2010) and the results of this study demonstrated that GAG chains were shorter in the NP compared with the AC. Consequently, differential GAG chain length might contribute to the higher moduli of the AC. Variability in aggrecan structure may also be a consequence of differential sulphation, as repulsion of adjacent negatively charged GAG chains along the aggrecan core protein can be modified by changes in solute concentration (Chandran and Horkay, 2012). Other groups show an age-related increase in KS chain length and abundance (Santer et al., 1982) and an increase in CS 4S/6S sulphation (Bayliss et al., 1999; Lauder et al., 2001; Plaas et al., 2001; Plaas et al., 1997), which could potentially affect the overall charge, repulsion and spacing of these GAGs and, therefore, affect aggrecan core protein extension. In mature, intact AC and NP, mean GAG chain length was significantly different between the tissues ( $p<0.01$; Fig. 1 ), suggesting that GAG-spacing-mediated variation in core protein

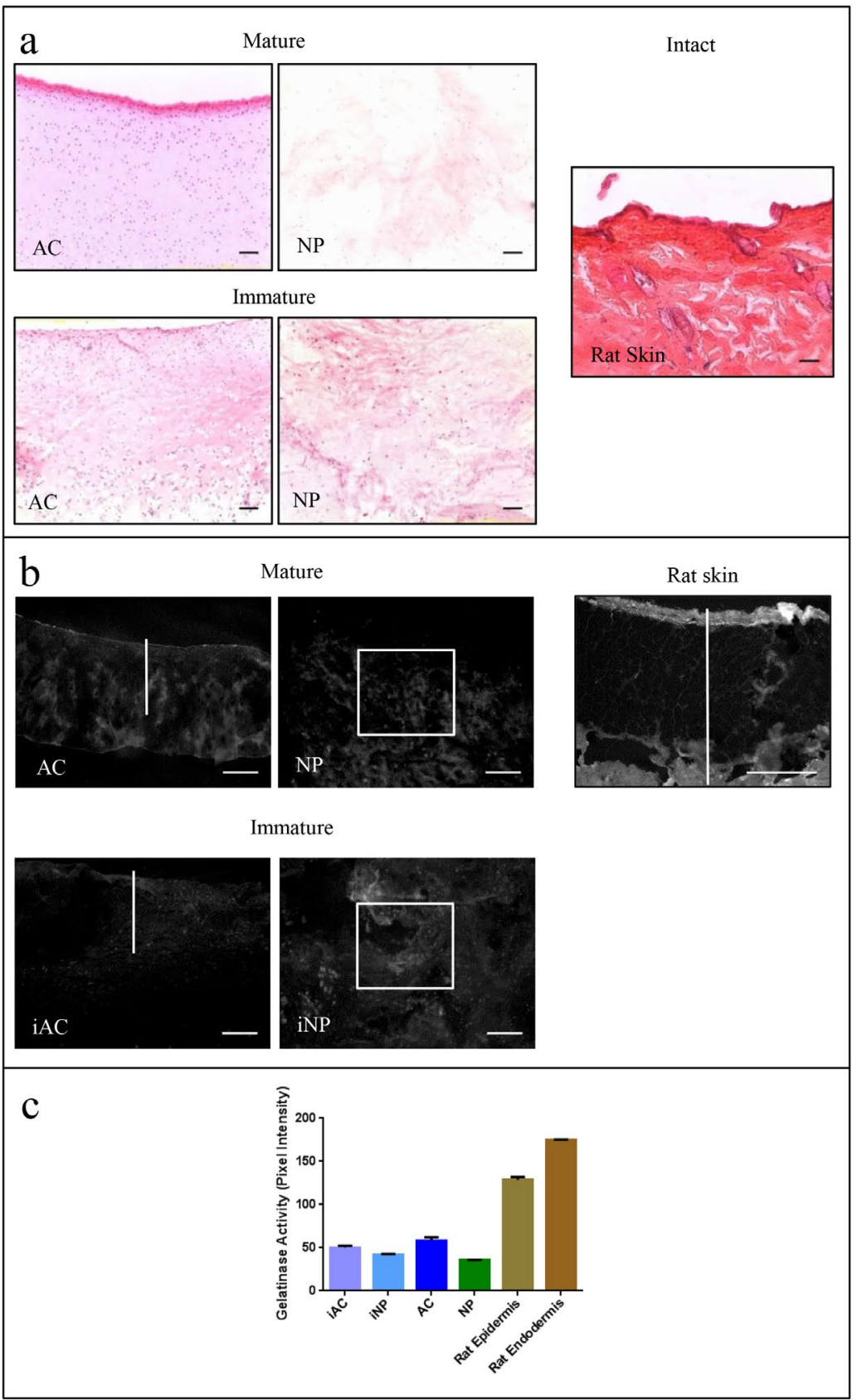

Fig. 7. Low levels of MMP activity in young healthy bovine AC and NP tissue. (a) Haematoxylin and eosin staining of healthy mature and immature (iAC, iNP) bovine AC and NP tissue and healthy rat skin. (b) Respective in situ gelatine zymography. White lines and boxes indicate regions measured for mean fluorescent activity. (c) Mean fluorescent gelatinase activity between iAC $(n=2)$, iNP $(n=2), \mathrm{AC}(n=2), \mathrm{NP}$ $(n=2)$ and rat skin $(n=2)$. Scale bars: $100 \mu \mathrm{m}$. 


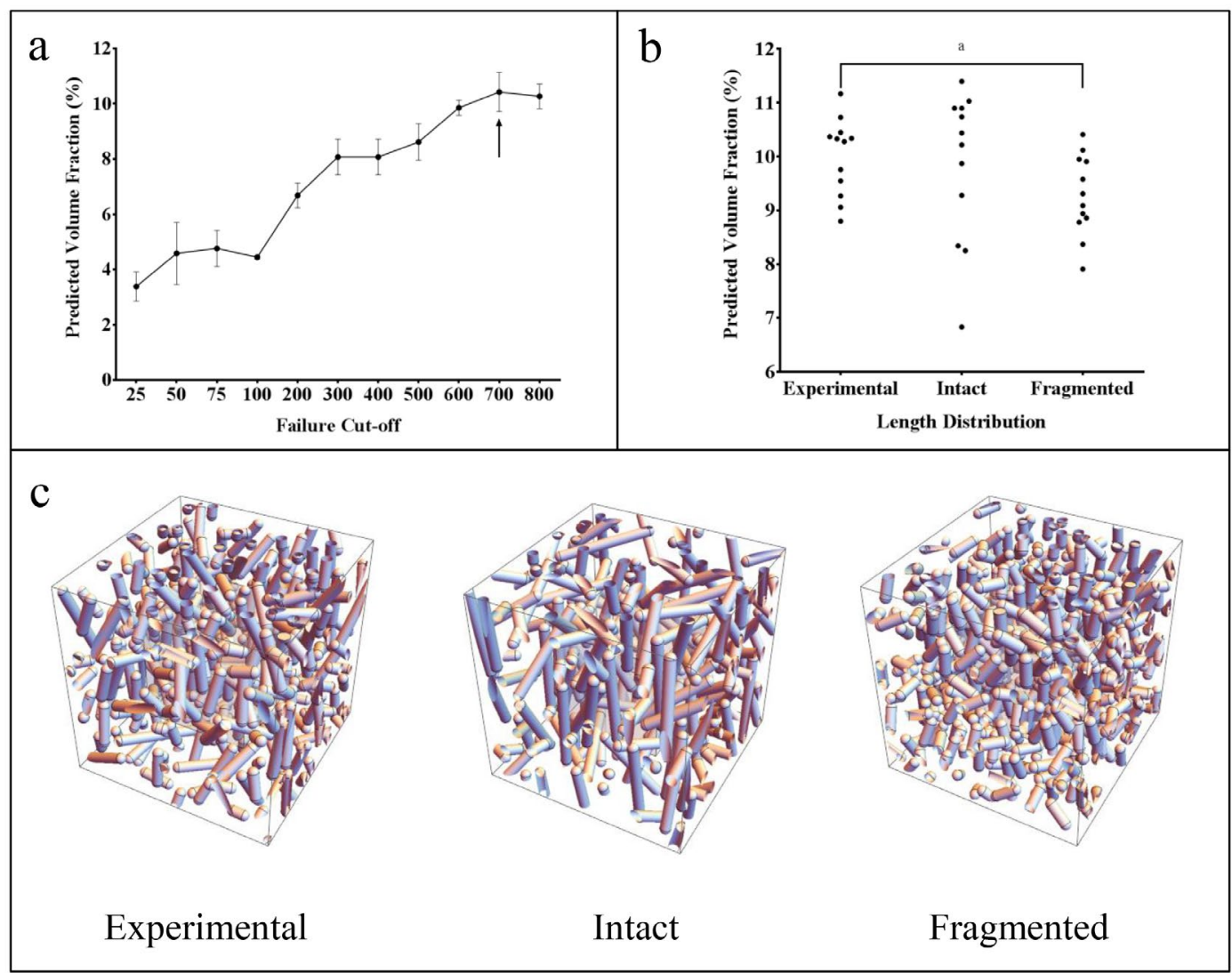

Fig. 8. Simulation of aggrecan packing. (a) To determine an appropriate number of failures before the algorithm terminated, the effect of this parameter on the predicted aggrecan volume fraction for intact aggrecan (bars represent standard deviation) was investigated. The predicted volume fraction stopped increasing after $c=700$ (arrow). (b) Predicted aggrecan volume fraction for each length distribution. The volume fraction predicted by the simulation of the experimental distribution had a high mean and low standard deviation compared with the intact and fragmented simulations. (c) Visual representation of the computational models of aggrecan packing within a set volume. ${ }^{\text {a }}$ indicates a significance of $p<0.001$.
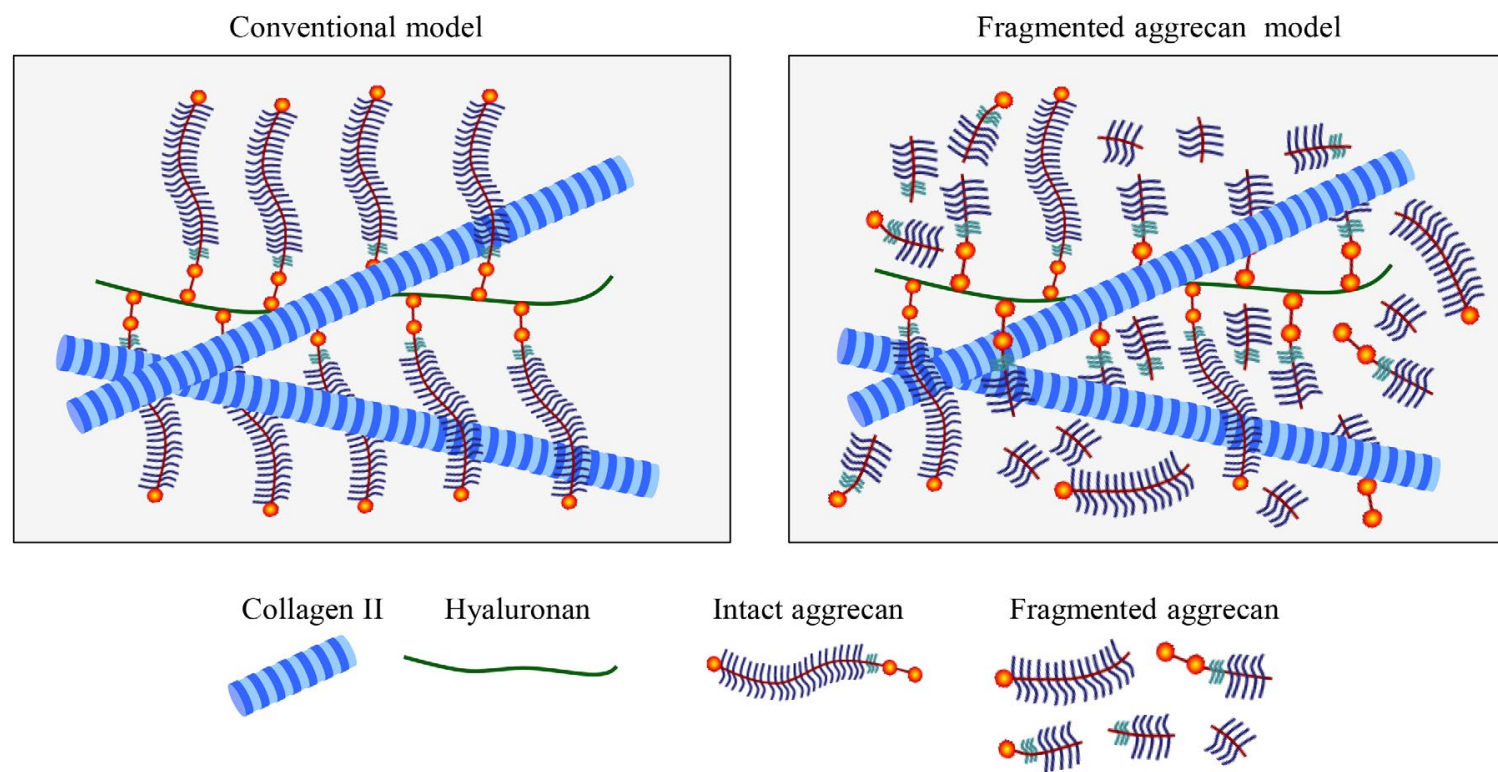

Fig. 9. Proteoglycan structure in cartilaginous ECM. Traditionally, aggrecans are depicted as an intact bottlebrush structures, forming aggregates through interaction with hyaluronan through their G1 domain. Data from this study challenged this conventional model: aggrecans were mostly fragmented within a cartilaginous matrix, whilst still being capable of generating an osmotic potential. 
Table 1. Reported aggrecanases and associated cleavage sites. Aggrecan cleavage is reported for members of the MMPs and a disintegrin and metalloproteinase with thrombospondin motifs (ADAMTs) families, Cathepsin and Calpain-2.

\begin{tabular}{|c|c|c|}
\hline Sequence & All proteases responsible for cleavage & Source publication \\
\hline $\begin{array}{l}\text { Asn }^{341}-\mathrm{Phe}^{342} \\
\text { (human and bovine) }\end{array}$ & $\begin{array}{c}\text { MMP-1, 3, 7, 9, 13, 14, } 19 \text {, and } 20 \text { at } \\
\text { neutral } \mathrm{pH} \text {, capthesin } \mathrm{B} \text { and } \mathrm{K} \text { at low } \\
\mathrm{pH}\end{array}$ & $\begin{array}{l}\text { Porter et al., (2005); Westling et al., } \\
\text { (2002); Hou et al., (2003); Mort et al., } \\
\text { (1998); Fosang et al., (1992) }\end{array}$ \\
\hline $\begin{array}{l}\text { NITEGE }^{373}-\text { ARGSV }^{374} \\
\text { (human and bovine) }\end{array}$ & ADAMTS-1, 4, 5, 8, 9, 11 and 15 & $\begin{array}{l}\text { Huang and Wu, (2008); Vo et al., } \\
\text { (2013); Porter et al., (2005); Pockert et } \\
\text { al., (2009); Abbaszade et al., (1999) }\end{array}$ \\
\hline $\mathrm{PGVA}^{709}-\mathrm{AVPV}^{710}$ & \multirow{5}{*}{ Calpain-2 (m) } & \multirow{5}{*}{$\begin{array}{c}\text { Struglics and Larsson, (2010); Oshita } \\
\text { et al., (2004); Yamamoto et al., (1992); } \\
\text { Szomor et al., (1999); Maehara et al., } \\
\text { (2007) }\end{array}$} \\
\hline GDLS $^{954}$-GLPS $^{955}$ & & \\
\hline GDLS $^{1353}$-GLPS $^{1354}$ & & \\
\hline EDLS $^{1411}-R L P S^{1412}$ & & \\
\hline GDLS $^{1431}-$ GVPS $^{1432}$ & & \\
\hline Leu1462-Val1463 & Capthesin D & Handley et al., (2001) \\
\hline $\begin{array}{l}\text { ASELE }{ }^{1480}-\text { GRGTI }^{1481} \\
\text { (bovine) } \\
\text { ASELE }{ }^{1545}-\text { GRGTI }^{1546} \\
\text { (human) }\end{array}$ & ADAMTS-4, 5 & $\begin{array}{l}\text { Huang and Wu, (2008); } \\
\text { Pockert et al., (2009) }\end{array}$ \\
\hline Leu1654-Val1655 & Capthesin D & Handley et al., (2001) \\
\hline $\begin{array}{l}\text { FKEEE }^{1667}-\text { GLGSV }^{1668} \\
\text { (bovine) }^{1715} \\
\text { FKEEE }{ }^{1714}-\text { GLGSV }^{1715} \\
\text { (human) }\end{array}$ & ADAMTS-4, 5 & $\begin{array}{l}\text { Huang and Wu, (2008); } \\
\text { Pockert et al., (2009) }\end{array}$ \\
\hline $\begin{array}{l}\text { PTAQE }^{1771}-\text { AGEGP }^{1772} \\
\text { (bovine) } \\
\text { FKEEE }^{1714}-\text { GLGSV }^{1715} \\
\text { (human) }\end{array}$ & ADAMTS-4, 5, 9 & $\begin{array}{l}\text { Huang and } \mathrm{Wu},(2008) ; \\
\text { Pockert et al., (2009); } \\
\text { Somerville et al., (2003) }\end{array}$ \\
\hline Phe $^{1754}-V_{\text {Val }}{ }^{1755}$ & Capthesin D & Handley et al., (2001) \\
\hline Leu $^{1854}-$ Ile $^{1855}$ & Capthesin D & Handley et al., (2001) \\
\hline $\begin{array}{l}\text { TISQE }^{1871}-\text { LGQRP }^{1872} \\
\text { (bovine) } \\
\text { TISQE }^{1919} \text {-LGQRP } \\
\text { (human) }\end{array}$ & ADAMTS-1, 4, 5 & $\begin{array}{l}\text { Huang and Wu, (2008); } \\
\text { Kuno et al., (2000); } \\
\text { Pockert et al., (2009) }\end{array}$ \\
\hline
\end{tabular}

length was due to variation in GAG elongation, sulphation patterning or occupation of GAG substitution sites. These differences in the structure of NP and AC aggrecan might be an adaptive response to the differential in vivo mechanical environments within the tissues.

The influence of structural difference in intact aggrecan on tissue function might, however, be marginal. Intact monomers only accounted for a small population $(\approx 0.5-5 \%)$ of the total molecular population. Although aggrecan fragmentation was observed more than 20 years ago in baboon AC and IVD by Buckwalter and colleagues, the ratio of intact to fragmented molecules is not well characterised and molecular fragmentation is assumed to be a consequence of ageing (Buckwalter et al., 1994). More recent studies focus solely on characterising the population of intact aggrecan (Lee et al., 2013;
Lee et al., 2010). As non-intact aggrecan accounts for at least $95 \%$ of the molecules in both mature and developing tissues, aggrecan fragmentation is unlikely to be maladaptive. However, it is important to note that, in contrast to the textbook depiction, a large proportion of aggrecan molecules might be incapable of interacting with hyaluronan and the lack of structural heterogeneity, which was evident in the $\mathrm{AC}$, might be due, in part, to structural differences in molecules originating in the territorial and interterritorial matrices.

Enzymatic proteases are the most likely mediators of aggrecan fragmentation and Table 1 reports aggrecanases and their cleavage sites. Gelatine zymography is used to characterise relative aggrecanase activity in developing, diseased and degenerate tissues (Freemont et al., 1999; Gepstein et al., 2002; Weiler, 2013) and, crucially, MMP activity 
Table 2. Predicted protease specific amino acid sequence cleavage sites of aggrecan. Grey text indicates cleavage sites present in immature, pre-processed aggrecan. Black text indicates cleavage sites present in mature, processed aggrecan. ${ }^{*}=$ non-unique cleavage sites.

\begin{tabular}{|c|c|c|c|c|c|}
\hline Enzyme & $\begin{array}{l}\text { Cleavage } \\
\text { position }\end{array}$ & Cleavage sequence & $\begin{array}{c}\text { N-fragment } \\
\text { size (kDa) }\end{array}$ & $\begin{array}{l}\text { C-fragment } \\
\text { size (kDa) }\end{array}$ & Score \\
\hline \multirow{5}{*}{ Cathepsin-D } & 29 & DNSLISVSI & 3.21 & 280.68 & 0.96 \\
\hline & 83 & KEKEIVVLL & 9.22 & 274.67 & 1.00 \\
\hline & 461 & SEDLIVVQV & 54.45 & 229.43 & 0.99 \\
\hline & 699 & VEEW|IVTQ & 83.27 & 200.62 & 0.99 \\
\hline & 1537 & FSGLIPSGF & 180.24 & 103.65 & 0.99 \\
\hline \multirow{2}{*}{ Calpain-2 (m) } & 1681 & PDLSIGQPS & 197.24 & 86.65 & 0.95 \\
\hline & 2070 & PGLP|SATP & 242.21 & 41.68 & 1.00 \\
\hline MMP-2 & 1278 & TAGDIISGA & 149.63 & 134.26 & 1.00 \\
\hline \multirow{5}{*}{ MMP-3 } & $952^{*}$ & GVGD|LSGL & 112.17 & 171.72 & 0.99 \\
\hline & $971^{*}$ & GVGDlLSGL & 114.39 & 169.50 & 0.96 \\
\hline & 1351 & AVGDlLSGL & 158.03 & 125.85 & 0.95 \\
\hline & 1421 & EVLEIISAS & 166.22 & 117.67 & 0.96 \\
\hline & 1788 & GIAE|VSGE & 209.91 & 73.97 & 1.00 \\
\hline \multirow{8}{*}{ MMP-7 } & 263 & SPEK|FTFQ & 30.73 & 253.16 & 0.97 \\
\hline & 512 & SPEQ|LQAA & 60.48 & 223.41 & 0.95 \\
\hline & $952^{*}$ & GVGDlLSGL & 112.17 & 171.72 & 0.96 \\
\hline & $971^{*}$ & GVGD|LSGL & 114.39 & 169.50 & 0.94 \\
\hline & $1351^{*}$ & AVGDlLSGL & 158.03 & 125.85 & 0.98 \\
\hline & 1450 & VGTD|LSGL & 169.69 & 114.20 & 0.94 \\
\hline & 1488 & ASGDlLDLG & 174.20 & 109.68 & 0.99 \\
\hline & $1963^{*}$ & TAGDIISGA & 230.31 & 53.58 & 1.00 \\
\hline \multirow{2}{*}{ MMP-9 } & 868 & TAGDIISGA & 230.31 & 53.58 & 1.00 \\
\hline & $1963^{*}$ & TAGDIISGA & 230.31 & 53.58 & 1.00 \\
\hline
\end{tabular}

in the IVD is maximal during foetal development (Rutges et al., 2010). However, in the current study, only minimal gelatinase activity in neonatal and mature (yet young) tissues was detected. Therefore, as both AC and IVD continue to grow post-partum (as a consequence of new ECM synthesis), aggrecan fragmentation might peak during foetal development, but must also continue at low levels during the development of the young animal. Identifying which proteases drive this fragmentation is complicated by the structural heterogeneity of the fragmented aggrecan and the low substrate specificity of many ECM proteases (Chakraborti et al., 2003). The following aggrecanases are expressed in AC and/or IVD and are reported to cleave collagen II: MMP-2, -3,
$-7,-9,-10,-19$, cathepsins B, D, G (IVD only), H (AC only) and Calpain-2(m) (Ariga et al., 2001; Cawston and Wilson, 2006; Chakraborti et al., 2003; Fukuta et al., 2011; Gruber et al., 2011; Hamamura et al., 2013; Hembry et al., 2007; Hembry et al., 1995; Konttinen et al., 2002; Lipari and Gerbino, 2013; Minarowska et al., 2008; Nakase et al., 2000; Ohta et al., 1998; Okada et al., 1992; Ruettger et al., 2008; Salminen-Mankonen et al., 2007; Struglics and Hansson, 2010; Turk et al., 1997; Vittorio et al., 1986; Vo et al., 2013). Putative cleavage sites for a sub-set of these enzymes [cathepsin D, calpain-2(m) and MMP-2, -3, -7 and -9] can be predicted using the machine-learning approaches developed by the PROSPER project (Song et al., 2012) (Table 2,3). Each of these enzymes is predicted 
Table 3. Predicted protease specific amino acid sequence cleavage sites of collagen II. Grey text indicates cleavage sites present in immature, pre-processed aggrecan. Black text indicates cleavage sites present in mature, processed aggrecan.

\begin{tabular}{|c|c|c|c|c|c|}
\hline Enzyme & $\begin{array}{l}\text { Cleavage } \\
\text { position }\end{array}$ & Cleavage sequence & $\begin{array}{c}\text { N-fragment } \\
\text { size (kDa) }\end{array}$ & $\begin{array}{l}\text { C-fragment } \\
\text { size (kDa) }\end{array}$ & Score \\
\hline \multirow{3}{*}{ Cathepsin D } & 114 & DIKDIVGP & 13.42 & 175.35 & 0.96 \\
\hline & 143 & KGEKlGAPG & 17.29 & 171.48 & 0.93 \\
\hline & 1477 & EQEF/GVDI & 187.54 & 1.23 & 1.00 \\
\hline \multirow{3}{*}{ Calpain-2 (m) } & 509 & PGERlGAPG & 64.61 & 124.16 & 0.99 \\
\hline & 716 & QGLQ|GPRG & 91.64 & 97.13 & 1.00 \\
\hline & 1142 & QGLP|GPPG & 146.54 & 42.23 & 0.98 \\
\hline \multirow{2}{*}{ MMP-2 } & 499 & EPGGlVGPI & 63.30 & 125.47 & 0.95 \\
\hline & 805 & EKGElVGPP & 103.22 & 85.55 & 1.00 \\
\hline \multirow{6}{*}{ MMP-3 } & 37 & CVQDIGQRY & 4.23 & 184.54 & 0.98 \\
\hline & 103 & PGPK IGQKG & 11.95 & 176.82 & 0.96 \\
\hline & 111 & EPGDIIKDI & 13.07 & 175.70 & 0.94 \\
\hline & 134 & QGPRIGDRG & 16.00 & 172.77 & 1.00 \\
\hline & 344 & AGARlGNDG & 43.44 & 145.33 & 0.99 \\
\hline & 1451 & TVIElYRSQ & 184.37 & 4.40 & 0.95 \\
\hline \multirow{3}{*}{ MMP-7 } & 358 & PPGP|VGPA & 45.22 & 143.55 & 0.97 \\
\hline & 663 & GPSGIFQGL & 84.59 & 104.18 & 1.00 \\
\hline & 1204 & PPGN|PGPP & 154.38 & 34.39 & 0.94 \\
\hline \multirow{6}{*}{ MMP-9 } & 222 & GPQG|FQGN & 27.46 & 161.31 & 1.00 \\
\hline & 373 & APGAlKGEA & 47.11 & 141.67 & 0.96 \\
\hline & 798 & GPAGlANGE & 102.31 & 86.47 & 0.99 \\
\hline & 834 & GPAG|FAGP & 106.84 & 81.93 & 1.00 \\
\hline & 879 & GPTGlVTGP & 112.53 & 76.24 & 1.00 \\
\hline & 1006 & EPGKlQGAP & 128.95 & 59.82 & 0.94 \\
\hline
\end{tabular}

to cleave both ECM components, but cathepsin D is the only enzyme with predicted cleavage sites in processed aggrecan, but not processed collagen. Calpain-2 $(\mathrm{m})$ is present in both the AC and IVD and is the most likely candidate for C-terminal truncation of aggrecan, with three predicted cleavage sites in collagen II as well (Fukuta et al., 2011; Oshita et al., 2004).

Protease-driven fragmentation of aggrecan is likely to influence tissue function. Aggrecan structure mediates single molecule mechanics and GAG-GAG interactions account for 30-50 \% of the compressive modulus in the AC (Eisenberg and Grodzinsky, 1985; Seog et al., 2005). However, these models assume that aggrecan structure is homogeneous (with regards to core-protein length and GAG sulphation) rather than, as demonstrated in this study, heterogeneous (both within and between tissues) (Fig. 1-3). Our measurements of bovine AC stiffness were similar to those previously reported in healthy human cartilage (Seog et al., 2005; Treppo et al., 2000) and, consequently, the fragmentation, which was observed, did not adversely affect the compressive modulus. Therefore, contrary to previous models (Eisenberg and Grodzinsky, 1985; Seog et al., 2005), mechanically competent tissues could be comprised of fragmented, non-HA (hyaluronic acid)-associated aggrecan (Fig. 9). In addition, this work reported for the first time the nanomechanical stiffness of the NP, which is approximately one fifth compared 
with the AC. As over $95 \%$ of aggrecan molecules were fragmented in both tissues, the difference in compressive modulus between AC and NP were likely to be mediated by the aggrecan to collagen II ratio (Mwale et al., 2004).

Aggrecan fragmentation might indirectly influence tissue stiffness by mediating molecular packing density. Aggrecan concentration positively correlates with osmotic potential in the AC (Chandran and Horkay, 2012), whilst the density of aggrecanbound GAGs can influence mobility of water, solutes and proteins by modulating osmolarity and porosity (Gribbon and Hardingham, 1998). At high aggrecan concentrations, molecular diffusion through the unloaded ECM is significantly reduced, which may, in turn, influence the availability of oxygen and metabolites (Gribbon and Hardingham, 1998). However, in mechanically loaded matrices, theoretical studies predict that lower aggrecan concentrations may lead to reduced diffusivity (Wills et al., 2016). Porosity and permeability also affect resistance to compressive forces: using an ACmimetic hydrogel scaffold with a modulus similar to the AC, it is shown that tissue modulus is inversely correlated with micro-porosity and permeability (Vikingsson et al., 2015; Woodfield et al., 2004). In order to directly assess the effect of aggrecan fragmentation on the mechanical behaviour and porosity of the IVD constructs, it will be necessary to employ in vitro model systems where aggrecan structure can be modulated. Our computational simulations predicted that a heterogeneous aggrecan population was desirable in order to optimise molecular packing and it is suggested that enzymatic processing of aggrecan might be an important adaptive mechanism to mediate the structure and function of cartilaginous tissues.

\section{Conclusions}

The observation of extensive aggrecan fragmentation challenged our understanding of the pathology and tissue engineering of cartilaginous tissues. The increase in aggrecanase activity, which characterises degenerating tissues, is likely to result in further degradation of aggrecan into non-functional fragments, which are small enough to diffuse from the matrix; although, the extent to which these remodelling events are localised within the tissue remains unknown. When considering the development of viable tissue-engineered constructs for the repair of cartilaginous tissues, it might be necessary to replicate experimentally the structural heterogeneity of tissue aggrecan and to use computational approaches to more accurately model the interplay between the complex structure of cartilaginous tissues and key aspects of tissue function.

\section{Acknowledgements}

The authors gratefully acknowledge financial support from the University of Manchester Research Impact scholarship and Presidents Doctoral Scholarship. The authors are also grateful to Dr Thomas Jowitt and Hilda Diana Ruiz Nivia of the Biomolecular Analysis Core Facility. TS would like to thank the EPSRC for supporting his work through his fellowship grant (no. L017997/1). The authors declare no competing financial interests. All imaging and nanomechanical data acquisition were performed at the University of Manchester BioAFM facility.

\section{References}

Abbaszade I, Liu RQ, Yang F, Rosenfield SA, Ross $\mathrm{OH}$, Link JR, Ellis DM, Tortorella MD, Pratta MA, Hollis JM, Wynn R, Duke JL, George HJ, Hillman MC, Murphy K, Wiswall BH, Copeland RA, Decicco CP, Bruckner R, Nagase H, Itoh Y, Newton RC, Magolda RL, Trzaskos JM, Burn TC (1999) Cloning and characterization of ADAMTS11, an aggrecanase from the ADAMTS family. J Biol Chem 274: 2344323450.

Abramoff M, Magalhães P, Sunanda J (2004) Image processing with ImageJ. Biophotonics Intern 11: 3642.

Akhtar R, Cruickshank JK, Zhao X, Walton LA, Gardiner NJ, Barrett SD, Graham HK, Derby B, Sherratt MJ (2014) Localized micro- and nano-scale remodelling in the diabetic aorta. Acta biomater 10: 4843-4851.

Akhtar R, Sherratt MJ, Cruickshank JK, Derby B (2011) Characterizing the elastic properties of tissues. Mater Today (Kidlington) 14: 96-105.

Ariga K, Yonenobu K, Nakase T, Kaneko M, Okuda S, Uchiyama Y, Yoshikawa H (2001) Localization of cathepsins $\mathrm{D}, \mathrm{K}$, and $\mathrm{L}$ in degenerated human intervertebral discs. Spine (Phila Pa 1976) 26: 2666-2672.

Bayliss MT, Osborne D, Woodhouse S, Davidson C (1999) Sulfation of chondroitin sulfate in human articular cartilage. The effect of age, topographical position, and zone of cartilage on tissue composition. J Biol Chem 274: 15892-15900.

Buckwalter JA, Pedrini-Mille A, Pedrini V, Tudisco C (1985) Proteoglycans of human infant intervertebral disc. Electron microscopic and biochemical studies. J Bone Joint Surg Am 67: 284-294.

Buckwalter JA, Roughley PJ, Rosenberg LC (1994) Age-related changes in cartilage proteoglycans: quantitative electron microscopic studies. Microsc Res Tech 28: 398-408.

Buckwalter JA, Smith KC, Kazarien LE, Rosenberg LC, Ungar R (1989) Articular cartilage and intervertebral disc proteoglycans differ in structure: an electron microscopic study. J Orthop Res 7: 146151. 
Cawston TE, Wilson AJ (2006) Understanding the role of tissue degrading enzymes and their inhibitors in development and disease. Best Pract Res Clin Rheumatol 20: 983-1002.

Chakraborti S, Mandal M, Das S, Mandal A, Chakraborti T (2003) Regulation of matrix metalloproteinases: an overview. Mol Cell Biochem 253: 269-285.

Chandran PL, Dimitriadis EK, Basser PJ, Horkay F (2010) Probing interactions between aggrecan and mica surface by the atomic force microscopy. J Polym Sci B Polym Phys 48: 2575-2581.

Chandran PL, Horkay F (2012) Aggrecan, an unusual polyelectrolyte: review of solution behavior and physiological implications. Acta Biomater 8: 3-12.

Colombier P, Clouet J, Hamel O, Lescaudron L, Guicheux J (2014) The lumbar intervertebral disc: from embryonic development to degeneration. Joint Bone Spine 81: 125-129.

Eisenberg SR, Grodzinsky AJ (1985) Swelling of articular cartilage and other connective tissues: electromechanochemical forces. J Orthop Res 3: 148159.

El Bakali J, Gras-Masse H, Maingot L, Deprez B, Dumont J, Leroux F, Deprez-Poulain R (2014) Inhibition of aggrecanases as a therapeutic strategy in osteoarthritis. Future Med Chem 6: 1399-1412.

Fang M, Goldstein EL, Turner AS, Les CM, Orr BG, Fisher GJ, Welch KB, Rothman ED, Banaszak MM (2012) Type I collagen D-spacing in fibril bundles of dermis, tendon, and bone: bridging between nanoand micro-level tissue hierarchy. ACS Nano 6: 95039514.

Fosang AJ, Neame PJ, Last K, Hardingham TE, Murphy G, Hamilton JA (1992) The interglobular domain of cartilage aggrecan is cleaved by PUMP, gelatinases, and cathepsin B. J Biol Chem 267: $19470-$ 19474.

Freemont AJ, Byers RJ, Taiwo YO, Hoyland JA (1999) In situ zymographic localisation of type II collagen degrading activity in osteoarthritic human articular cartilage. Ann Rheum Dis 58: 357-365.

Fukuta S, Miyamoto K, Suzuki K, Maehara H, Inoue T, Hara A, Kikuike K, Taguchi A, Shimizu K (2011) Abundance of calpain and aggrecancleavage products of calpain in degenerated human intervertebral discs. Osteoarthritis Cartilage 19: 12541262.

Gepstein A, Shapiro S, Arbel G, Lahat N, Livne E (2002) Expression of matrix metalloproteinases in articular cartilage of temporomandibular and knee joints of mice during growth, maturation, and aging. Arthritis Rheum 46: 3240-3250.

Graham JS, Vomund AN, Phillips CL, Grandbois M (2004) Structural changes in human type I collagen fibrils investigated by force spectroscopy. Exp Cell Res 299: 335-342.

Graham HK, Trafford AW (2007) Spatial disruption and enhanced degradation of collagen with the transition from compensated ventricular hypertrophy to symptomatic congestive heart failure. Am J Physiol Heart Circ Physiol 292: H1364-1372.

Graham HK, Akhtar R, Kridiotis C, Derby K, Kundu T, Trafford AW, Sherratt MJ (2011) Localised micro-mechanical stiffening in the ageing aorta. Mech Ageing Dev 132: 459-467.

Greene MA, Loeser RF (2015) Aging-related inflammation in osteoarthritis. Osteoarthritis Cartilage 23: 1966-1971.

Gribbon P, Hardingham TE (1998) Macromolecular diffusion of biological polymers measured by confocal fluorescence recovery after photobleaching. Biophys J 75: 1032-1039.

Gruber HE, Ingram JA, Hoelscher GL, Zinchenko N, Norton HJ, Hanley EN, Jr. (2011) Constitutive expression of cathepsin $\mathrm{K}$ in the human intervertebral disc: new insight into disc extracellular matrix remodeling via cathepsin $\mathrm{K}$ and receptor activator of nuclear factor-kappaB ligand. Arthritis Res Ther 13: R140.

Hamamura K, Zhang P, Zhao L, Shim JW, Chen A, Dodge TR, Wan Q, Shih H, Na S, Lin CC, Sun HB, Yokota H (2013) Knee loading reduces MMP13 activity in the mouse cartilage. BMC Musculoskelet Disord 14: 312.

Handley CJ, Mok MT, Ilic MZ, Adcocks C, Buttle DJ, Robinson HC (2001) Cathepsin D cleaves aggrecan at unique sites within the interglobular domain and chondroitin sulfate attachment regions that are also cleaved when cartilage is maintained at acid $\mathrm{pH}$. Matrix Biol 20: 543-553.

Hembry RM, Bagga MR, Reynolds JJ, Hamblen DL (1995) Immunolocalisation studies on six matrix metalloproteinases and their inhibitors, TIMP-1 and TIMP-2, in synovia from patients with osteo- and rheumatoid arthritis. Ann Rheum Dis 54: 25-32.

Hembry RM, Atkinson SJ, Murphy G (2007) Assessment of gelatinase expression and activity in articular cartilage. Methods Mol Med 135: 227-238.

Holmes DF, Kadler KE (2006) The 10+4 microfibril structure of thin cartilage fibrils. Proc Natl Acad Sci U S A 103: 17249-17254.

Horcas I, Fernandez R, Gomez-Rodriguez JM, Colchero J, Gomez-Herrero J, Baro AM (2007) WSXM: a software for scanning probe microscopy and a tool for nanotechnology. Rev Sci Instrum 78: 013705.

Hou WS, Li Z, Buttner FH, Bartnik E, Bromme D (2003) Cleavage site specificity of cathepsin K toward cartilage proteoglycans and protease complex formation. Biol Chem 384: 891-897.

Huang K, Wu LD (2008) Aggrecanase and aggrecan degradation in osteoarthritis: a review. J Int Med Res 36: 1149-1160

Iijima H, Aoyama T, Ito A, Tajino J, Nagai M, Zhang X, Yamaguchi S, Akiyama H, Kuroki H (2014) Immature articular cartilage and subchondral bone covered by menisci are potentially susceptive to mechanical load. BMC musculoskelet Disord 15: 101.

Issy AC, Castania V, Castania M, Salmon CE, Nogueira-Barbosa MH, Bel ED, Defino HL 
(2013) Experimental model of intervertebral disc degeneration by needle puncture in Wistar rats. Braz J Med Biol Res 46: 235-244.

Jowitt TA, Murdoch AD, Baldock C, Berry R, Day JM, Hardingham TE (2010) Order within disorder: aggrecan chondroitin sulphate-attachment region provides new structural insights into protein sequences classified as disordered. Proteins 78: 33173327.

Kienle S, Gallei M, Yu H, Zhang B, Krysiak S, Balzer BN, Rehahn M, Schluter AD, Hugel T (2014) Effect of molecular architecture on single polymer adhesion. Langmuir 30: 4351-4357.

Kocsis E, Trus BL, Steer CJ, Bisher ME, Steven AC (1991) Image averaging of flexible fibrous macromolecules: the clathrin triskelion has an elastic proximal segment. J Struct Biol 107: 6-14.

Konttinen YT, Kaapa E, Hukkanen M, Gu XH, Takagi M, Santavirta S, Alaranta H, Li TF, Suda A (1999) Cathepsin G in degenerating and healthy discal tissue. Clin Exp Rheumatol 17: 197-204.

Konttinen YT, Mandelin J, Li TF, Salo J, Lassus J, Liljestrom M, Hukkanen M, Takagi M, Virtanan I, Santavirta S (2002) Acidic cysteine endoproteinase cathepsin $\mathrm{K}$ in the degeneration of the superficial articular hyaline cartilage in osteoarthritis. Arthritis Rheum 46: 953-960.

Kulicke W-M, Clasen C (2004) Viscosimetry of polymers and polyelectrolytes. Stem Cell Res Ther 1: 18.

Lauder RM, Huckerby TN, Brown GM, Bayliss MT, Nieduszynski IA (2001) Age-related changes in the sulphation of the chondroitin sulphate linkage region from human articular cartilage aggrecan. Biochem J 358: 523-528.

Lee HY, Kopesky PW, Plaas A, Sandy J, Kisiday J, Frisbie D, Grodzinsky AJ, Ortiz C (2010) Adult bone marrow stromal cell-based tissue-engineered aggrecan exhibits ultrastructure and nanomechanical properties superior to native cartilage. Osteoarthritis Cartilage 18: 1477-1486.

Lee HY, Han L, Roughley PJ, Grodzinsky AJ, Ortiz C (2013) Age-related nanostructural and nanomechanical changes of individual human cartilage aggrecan monomers and their glycosaminoglycan side chains. J Struct Biol 181: 264-273.

Lipari L, Gerbino A (2013) Expression of gelatinases (MMP-2, MMP-9) in human articular cartilage. Int J Immunopathol Pharmacol 26: 817-823.

Maehara H, Suzuki K, Sasaki T, Oshita H, Wada E, Inque T, Shimizu K (2007) G1-G2 aggrecan product that can be generated by $\mathrm{M}$-calpain on truncation at Ala709-Ala710 is present abundantly in human articular cartilage. J Biochem 141: 469-477.

Kuno K, Okada Y, Kawashima H, Nakamura H, Miyasaka M, Ohno H, Matsushima K (2000) ADAMTS-1 cleaves a cartilage proteoglycan, aggrecan. FEBS Lett 478: 241-245.

Malfait AM (2016) Osteoarthritis year in review 2015: biology. Osteoarthritis Cartilage 24: 21-26.
McConnell JC, O'Connel OV, Brennan K, Weiping L, Howe M, Joseph L, Knight D, O'Cualain R, Lim Y, Leek A, Waddington R, Rogan J, Astley SM, Gandhi A, Kirwan CC, Sherratt MJ, Streuli CH (2016) Increased peri-ductal collagen micro-organization may contribute to raised mammographic density. Breast Cancer Res 18: 5.

Minarowska A, Gacko M, Karwowska A, Minarowski L (2008) Human cathepsin D. Folia Histochem Cytobiol 46: 23-38.

Mort JS, Magny MC, Lee ER (1998) Cathepsin B: an alternative protease for the generation of an aggrecan 'metalloproteinase' cleavage neoepitope. Biochem J 335: 491-494.

Musumeci G, Castrogiovanni P, Trovato FM, Di Giunta A, Loreto C, Castorina S (2013) Microscopic and macroscopic anatomical features in healthy and osteoarthritic knee cartilage. OA Anatomy 1: 30.

Mwale F, Roughley P, Antoniou J (2004) Distinction between the extracellular matrix of the nucleus pulposus and hyaline cartilage: a requisite for tissue engineering of intervertebral disc. Eur Cell Mater 8: 58-64.

Nakase T, Kaneko M, Tomita T, Myoui A, Ariga K, Sugamoto K, Uchiyama Y, Ochi T, Yoshikawa H (2000) Immunohistochemical detection of cathepsin $\mathrm{D}, \mathrm{K}$, and $\mathrm{L}$ in the process of endochondral ossification in the human. Histochem Cell Biol 114: 21-27.

Ng L, Grodzinsky AJ, Patwari P, Sandy J, Plaas A, Ortiz C (2003) Individual cartilage aggrecan macromolecules and their constituent glycosaminoglycans visualized via atomic force microscopy. J Struct Biol 143: 242-257.

Nguyen Q, Liu J, Roughley PJ, Mort JS (1991) Link protein as a monitor in situ of endogenous proteolysis in adult human articular cartilage. Biochem J 278: 143-147.

Nguyen Q, Mort JS, Roughley PJ (1990) Cartilage proteoglycan aggregate is degraded more extensively by cathepsin L than by cathepsin B. Biochem J 266: 569-573.

Ohta S, Imai K, Yamashita K, Matsumoto T, Azumano I, Okada Y (1998) Expression of matrix metalloproteinase 7 (matrilysin) in human osteoarthritic cartilage. Lab Invest 78: 79-87.

Okada Y, Shinmei M, Tanaka O, Naka K, Kimura A, Nakanishi I, Bayliss MT, Iwata K, Nagase H (1992) Localization of matrix metalloproteinase 3 (stromelysin) in osteoarthritic cartilage and synovium. Lab Invest 66: 680-690.

Oshita H, Sandy JD, Suzuki K, Akaike A, Bai Y, Sasaki T, Shimizu K (2004) Mature bovine articular cartilage contains abundant aggrecan that is C-terminally truncated at Ala719-Ala720, a site which is readily cleaved by m-calpain. Biochem J 382: 253259.

Pelletier JP, Boileau C, Boily M, Brunet J, Mineau F, Geng C, Reboul P, Laufer S, Lajeunesse D, MartelPelletier J (2005) The protective effect of licofelone on experimental osteoarthritis is correlated with the downregulation of gene expression and protein 
synthesis of several major cartilage catabolic factors: MMP-13, cathepsin K and aggrecanases. Arthritis Res Ther 7: R1091-1102.

Plaas AH, Wong-Palms S, Roughley PJ, Midura RJ, Hascall VC (1997) Chemical and immunological assay of the nonreducing terminal residues of chondroitin sulfate from human aggrecan. J Biol Chem 272: $20603-$ 20610.

Plaas AH, West L, Midura RJ, Hascall VC (2001) Disaccharide composition of hyaluronan and chondroitin/dermatan sulfate. Analysis with fluorophore-assisted carbohydrate electrophoresis. Methods Mol Biol 171: 117-128.

Plodinec M, Loparic M, Aebi U (2010) Atomic force microscopy for biological imaging and mechanical testing across length scales. Cold Spring Harb Protoc 10: 86 .

Pockert AJ, Richardson SM, Le Maitre CL, Lyon M, Deakin JA, Buttle DJ, Freemont AJ, Hoyland JA (2009) Modified expression of the ADAMTS enzymes and tissue inhibitor of metalloproteinases 3 during human intervertebral disc degeneration. Arthritis Rheum 60: 482-491.

Porter S, Clark IM, Kevorikian L, Edwards DR (2005) The ADAMTS metalloproteinases. Biochem J 386: 15-27.

Rezakhaniha R, Agianniotis A, Schrauwen JT, Griffa A, Sage D, Bouten CV, van de Vosse FN, Unser M, Stergiopulos N (2012) Experimental investigation of collagen waviness and orientation in the arterial adventitia using confocal laser scanning microscopy. Biomech Model Mechanobiol 11: 461-473.

Roberts S, Evans EH, Kletsas D, Jaffray DC, Eisenstein SM (2006) Senescence in human intervertebral discs. Eur Spine J 15: S312-316.

Roughley PJ, Geng Y, Mort JS (2014) The nonaggregated aggrecan in the human intervertebral disc can arise by a non-proteolytic mechanism. Eur Cell Mater 28: 129-136.

Ruettger A, Schueler S, Mollenhauer JA, Wiederanders B (2008) Cathepsins B, K, and L are regulated by a defined collagen type II peptide via activation of classical protein kinase $\mathrm{C}$ and p38 MAP kinase in articular chondrocytes. J Biol Chem 283: 1043-1051.

Rutges JP, Nikkels PG, Oner FC, Ottink KD, Verbout AJ, Castelein RJ, Creemers LB, Dhert WJ (2010) The presence of extracellular matrix degrading metalloproteinases during fetal development of the intervertebral disc. Euro Spine J 19: 1340-1346.

Salminen-Mankonen HJ, Morko J, Vuorio E (2007) Role of cathepsin K in normal joints and in the development of arthritis. Curr Drug Targets 8: 315-323.

Santer V, White RJ, Roughley PJ (1982) O-Linked oligosaccharides of human articular cartilage proteoglycan. Biochim Biophys Acta 716: 277-282.

Seog J, Dean D, Rolauffs B, Wu T, Genzer J, Plaas AH, Grodzinsky AJ, Ortiz C (2005) Nanomechanics of opposing glycosaminoglycan macromolecules. J Biomech 38: 1789-1797.
Sherratt MJ (2009) Tissue elasticity and the ageing elastic fibre. Age (Dordr) 31: 305-325.

Sherratt MJ, Holmes DF, Shuttleworth CA, Kielty CM (2004) Substrate-dependent morphology of supramolecular assemblies: fibrillin and type-VI collagen microfibrils. J Biophys 86: 3211-3222.

Sivan SS, Wachtel E, Tsitron E, Sakkee N, van der Ham F, Degroot J, Roberts S, Maroudas A (2008) Collagen turnover in normal and degenerate human intervertebral discs as determined by the racemization of aspartic acid. J Biol Chem 283: 87968801.

Sivan SS, Wachtel E, Roughley P (2014) Structure, function, aging and turnover of aggrecan in the intervertebral disc. Biochim Biophysic Acta 1840: 3181-3189.

Smith LJ, Nerurkar NL, Choi KS, Harfe BD, Elliott DM (2011) Degeneration and regeneration of the intervertebral disc: lessons from development. Dis Model Mech 4: 31-41.

Somerville RP, Longpre JM, Jungers KA, Engle JM, Ross M, Evanko S, Wight TN, Leduc R, Apte SS (2003) Characterization of ADAMTS-9 and ADAMTS-20 as a distinct ADAMTS subfamily related to Caenorhabditis elegans GON-1. J Biol Chem 278: 9503-9513.

Song J, Tan H, Perry AJ, Akutsu T, Webb GI, Whisstock JC, Pike RN (2012) PROSPER: an integrated feature-based tool for predicting protease substrate cleavage sites. PloS One 7: e50300.

Sophia Fox AJ, Bedi A, Rodeo SA (2009) The basic science of articular cartilage: structure, composition, and function. Sports health 1: 461-468.

Struglics A, Hansson M (2010) Calpain is involved in C-terminal truncation of human aggrecan. Biochem J 430: 531-538.

Struglics A, Larsson S (2010) A comparison of different purification methods of aggrecan fragments from human articular cartilage and synovial fluid. Matrix Biol 29: 74-83.

Su HN, Chen ZH, Liu SB, Qiao LP, Chen XL, He HL, Zhao X, Zhou BC, Zhang YZ (2012) Characterization of bacterial polysaccharide capsules and detection in the presence of deliquescent water by atomic force microscopy. Appl Environ Microbiol 78: 3476-3479.

Szomor Z, Shimizu K, Yamamoto S, Yasuda T, Ishikawa H, Nakamura T (1999) Externalization of calpain (calcium-dependent neutral cysteine proteinase) in human arthritic cartilage. Clin Exp Rheumatol 17: 569-574.

Sztrolovics R, Alini M, Roughley PJ, Mort JS (1997) Aggrecan degradation in human intervertebral disc and articular cartilage. Biochem J 326: 235-241.

Tewari A, Grys K, Kollet J, Sarkany R, Young AR (2014) Upregulation of MMP12 and its activity by UVA1 in human skin: potential implications for photoaging. J Invest Dermatol 134: 2598-2609.

Treppo S, Koepp H, Quan EC, Cole AA, Kuettner KE, Grodzinsky AJ (2000) Comparison of biomechanical and biochemical properties of cartilage 
from human knee and ankle pairs. J Ortho Res 18: 739-748.

Turk B, Turk V, Turk D (1997) Structural and functional aspects of papain-like cysteine proteinases and their protein inhibitors. Biol Chem 378: 141-150.

Vedicherla S, Buckley CT (2016) Cell-based therapies for intervertebral disc and cartilage regeneration - current concepts, parallels and perspectives. J Ortho Res 35: 8-22.

Vikingsson L, Claessens B, Gomez-Tejedor JA, Gallego Ferrer G, Gomez Ribelles JL (2015) Relationship between micro-porosity, water permeability and mechanical behavior in scaffolds for cartilage engineering. J Mech Behav Biomed Mater 48: 60-69.

Vittorio N, Crissman JD, Hopson CN, Herman JH (1986) Histologic assessment of cathepsin D in osteoarthritic cartilage. Clin Exp Rheumatol 4: 221230.

Vo NV, Hartman RA, Yurube T, Jacobs LJ, Sowa GA, Kang JD (2013) Expression and regulation of metalloproteinases and their inhibitors in intervertebral disc aging and degeneration. Spine J 13: 331-341.

Wallace JM (2015) Effects of fixation and demineralization on bone collagen D-spacing as analyzed by atomic force microscopy. Connective Tissue Res 56: 68-75.

Wang F, Cai F, Shi R, Wang XH, Wu XT (2016) Aging and age related stresses: a senescence mechanism of intervertebral disc degeneration. Osteoarthritis Cartilage 24: 398-408.

Weiler C (2013) In situ analysis of pathomechanisms of human intervertebral disc degeneration. Pathologe 34: 251-259.

Westling J, Fosang AJ, Last $\mathrm{K}$, Thompson VP, Tomkinson KN, Herbert T, McDonagh T, Collins-Racie LA, Lavallie ER, Morris EA, Sansy JD (2002). ADAMTS4 cleaves at the aggrecanase site (Glu373-Ala374) and secondarily at the matrix metalloproteinase site (Asn341-Phe342) in the aggrecan interglobular domain. J Biol Chem 277: 16059-16066.

Wills CR, Malandrino A, Van Rijsbergen M, Lacroix D, Ito K, Noailly J (2016) Simulating the sensitivity of cell nutritive environment to composition changes within the intervertebral disc. J Mech Phys Solids 90: 108-123.

Woodfield TB, Malda J, de Wijn J, Peters F, Riesle J, van Blitterswijk CA (2004) Design of porous scaffolds for cartilage tissue engineering using a threedimensional fiber-deposition technique. Biomaterials 25: 4149-4161.

Yamamoto S, Shimizu K, Suzuki K, Nakagawa Y, Yamamuro T (1992) Calcium-dependent cysteine proteinase (calpain) in human arthritic synovial joints. Arthritis Rheum 35: 1309-1317.

Yu J, Tirlapur U, Fairbank J, Handford P, Roberts S, Winlove CP, Cui Z, Urban J (2007) Microfibrils, elastin fibres and collagen fibres in the human intervertebral disc and bovine tail disc. J Anat 210: 460-471.

Zeckser J, Wolff M, Tucker J, Goodwin J (2016) Multipotent mesenchymal stem cell treatment for discogenic low back pain and disc degeneration. Stem Cells Int 2: 1-13.

Zhao CQ, Wang LM, Jiang LS, Dai LY (2007) The cell biology of intervertebral disc aging and degeneration. Ageing Res Rev 6: 247-261.

\section{Web References}

1. https: //github.com/maxozo/Agracan_Length_ Volume_AFM

\section{Discussion with Reviewers}

Jérôme Noailly: Should aggrecan aggregates with folded molecules (as found in native tissues) be considered, would the benefit of partial fragmentation still be relevant in terms of packing and increase of the effective fixed charge density?

Authors: The influence of aggrecan ultrastructure and inter- and intra-molecular interactions on the predicted structure and functionality of cartilaginous tissues is an extremely interesting area, which would be important to address in future studies.

James Melrose: Have the authors considered the aggrecan fragmentation in terms of matricryptin generation? The G3 domains have some interesting interactive modules with potential cryptic biological properties. While, into the synovial fluid, these domains are released from the cartilage, this is different in the IVD. A few matricryptin fragments, such as Link-N and Peniel 2000, which are fragments of link protein and biglycan, affects disc cell metabolism. Aggrecan G3 contains complement, lectin and epidermal growth factor (EGF) motifs, which might also have interesting biological properties.

Authors: The potential generation of matricyptic sites and soluble matrikines as a consequence of aggrecan fragmentation is very interesting. Whilst there are computational methods available (such as the PROSPER protease specificity prediction server; additional Web Ref. 1) to predict protein cleavage sites, the complexity of the proteolytic environment and uncertainty as to the biological effects of any given peptide sequences may make identification of potential matricryptin and matrikine action difficult. As a consequence, experimental approaches to define the response of cells to differentially-fragmented aggrecan may prove most fruitful.

James Melrose: NP and cartilage differ in terms of the longevity of the aggrecan fragments, which remain within the tissue. In cartilage, when aggrecan 
undergoes proteolysis within the IGD, the G1containing fragment remains within the tissue attached to HA, but the remainder diffuses out of the cartilage into the synovial fluid. This does not happen in the NP, where aggrecan fragments remain in the IVD and accumulate with ageing. Could the authors comment on how they envisage this would affects tissue material properties? How much do the aggrecan fragments contribute to the reduction of the water in the disc and to its hydrodynamic weightbearing properties? Do feedback effects by these fragments on disc cells affect aggrecan biosynthesis? Is this a reason why aggrecan levels in the IVD decline with ageing?

Authors: The fragmentation process appeared to cleave both the core protein (leading to shorter molecules) and the GAG chains (for example the average GAG length in the $A C$ is $18.1 \mathrm{~nm}$ in intact molecules and $14.5 \mathrm{~nm}$ in fragmented molecules). Therefore, each fragment would have a lower total hydrophilicity than an intact molecule. However, the computational modelling approach adopted suggested that these fragmented molecules (if they were sufficiently large to be retained in the tissue) could pack more densely intact molecules. As a consequence, the negative charge per unit volume (and hence hydrophilicity) would be higher. Therefore, fragmentation would aid the dynamic weight-bearing properties of the tissue. This prediction could be experimentally tested using systems employing tuneable model aggrecan molecules.

\section{Additional Web Reference}

1. https://prosper.erc.monash.edu.au/

Editor's note: The Scientific Editor responsible for this paper was Stephen Ferguson. 